\title{
EAQUATE - An International Experiment For Hyper-spectral Atmospheric Sounding Validation
}

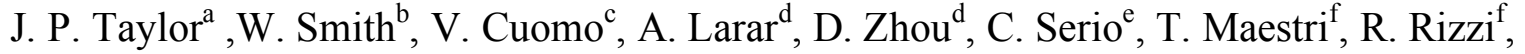

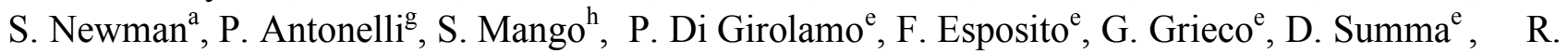

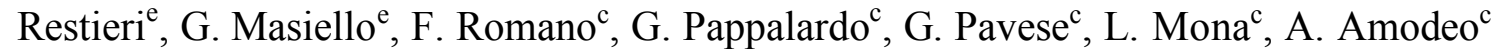 \\ and G. Pisani ${ }^{\mathrm{i}}$ \\ ${ }^{a}$ Met Office, Exeter Devon UK \\ ${ }^{\mathrm{b}}$ Hampton University, Hampton VA USA \\ 'IMAA - Istituto di Metodologie per l'Analisi Ambientale - CNR, Tito Scalo (Italy) \\ ${ }^{\mathrm{d}}$ NASA Langley Research Center, Hampton, VA USA \\ ${ }^{\text {}}$ DIFA - Dip. di Ingegneria e Fisica dell'Ambiente - University of Basilicata, Potenza (Italy) \\ ${ }^{\mathrm{f}}$ ADGB- Physics Department - Alma Mater Studiorum, University of Bologna, Bologna (Italy) \\ ${ }^{\mathrm{g}}$ Meditterainean Agency for Remote Sensing, Benevento IT \\ ${ }^{\mathrm{h}}$ NPOESS Integrated Program Office, Silver Spring, MD USA \\ ${ }^{i}$ CNISM - Consorzio Nazionale Interuniversitario per le Scienze fisiche della Materia - University of \\ Naples, Napoli (Italy)
}




\begin{abstract}
.
The international experiment called EAQUATE (European AQUA Thermodynamic Experiment) was held in September 2004 in Italy and the United Kingdom to demonstrate certain ground-based and airborne systems useful for validating hyperspectral satellite sounding observations. A range of

flights over land and marine surfaces were conducted to coincide with overpasses of the AIRS instrument on the EOS Aqua platform. Direct radiance evaluation of AIRS using NAST-I and SHIS has shown excellent agreement. Comparisons of level 2 retrievals of temperature and water vapor from AIRS and NAST-I validated against high quality lidar and drop sonde data show that the $1 \mathrm{~K} / 1 \mathrm{~km}$ and $10 \% / 1 \mathrm{~km}$ requirements for temperature and water vapor (respectively) are generally being met. The EAQUATE campaign has proven the need for synergistic measurements from a range of observing systems for satellite cal/val and has paved the way for future cal/val activities in support of IASI on the European Metop platform and CrIS on the US NPP/NPOESS platform.
\end{abstract}




\section{Capsule}

The validation of advanced Infra-Red sounding satellites requires a diverse set of coordinated synergistic observations utilizing ground based and airborne instrumentation. 


\section{Introduction}

The EAQUATE (European AQUA Thermodynamic Experiment) was held in September 2004 in Italy and the United Kingdom to validate data from the (Atmospheric Infrared Sounder) AIRS instrument on the Earth Observing System (EOS) Aqua satellite. It also aimed to demonstrate how combinations of ground-based and airborne systems are useful for validating hyperspectral satellite sounding observations from satellites due for launch through this decade. The decade of hyperspectral atmospheric sounding began with the launch of the AIRS experiment of the EOS Aqua satellite during May, 2002. Soon to follow AIRS, the Infrared Atmospheric Sounding Interferometer (IASI) is to be launched aboard the operational METOP polar orbiting satellite, in October 2006, and the CrIS instrument is to be orbited aboard the NPP/NPOESS operational series of polar orbiters, in late 2009. Operational geostationary satellite imaging hyperspectral sounding instruments, modeled after the experimental Geosynchronous Imaging Fourier Transform Spectrometer (GIFTS), are being planned for implementation during the next decade.

The focus of this initial experiment was placed on the validation of the AIRS instrument on the EOS Aqua satellite. During the EAQUATE, the Proteus aircraft carrying five separate remote sensing instruments, the NAST-I, NAST-M, S-HIS, FIRSC, and micro-MAPS, was stationed in Naples Italy from 4 to11 September and Cranfield England UK from 11 to 19 September, 2004. During the Italian portion of the campaign, the Proteus under flew Aqua in coordination with ground-based remote sensing measurements, including several Raman LIDAR water vapor and temperature profilers and radiosondes, provided by the Istituto di Metodologie per l'Analisi Ambientale (IMAA), the Dipartimento di Ingegneria e Fisica dell'Ambiente (DIFA), University of Basilicata in Potenza and University of Napoli (UNINA) in Napoli, Italy. During the UK portion of the campaign, the Proteus under flights of Aqua were coordinated with the UK Facility for Airborne Atmospheric Measurements BAe146-301 aircraft which flew a large payload of in-situ measurement instruments, including dropsondes, and remote sensing instruments (e.g., the Airborne Research Interferometer Evaluation System (ARIES) interferometer spectrometer), useful for validating the Aqua satellite observations. A brief description of the instrumentation used in the EAQUATE campaign are given in section 2 followed by a description of some of the results from the Italian phase in section 3 and of the UK phase in section 4. Section 5 concludes with a discussion of the merits of calibration validation of satellite instruments and the required synergy of different observing systems.

\section{Instrumentation}

Proteus (IPO): The Proteus aircraft, sponsored by the DoD/NOAA/NASA Integrated Program Office (IPO) for the NPOESS (National Polar orbiting Operational Environmental Satellite System), carried five separate instruments, the NPOESS Airborne Sounding Testbed-Interferometer (NASTI), the NPOESS Airborne Sounding Testbed-Microwave (NAST-M), the Scanning High resolution Interferometer Sounder (S-HIS), the Far Infrared Spectrometer for Cirrus (FIRSC), and the Microscale Measurement of Atmospheric Pollution Sensor (MicroMAPS). The NAST-I has a spectral range of 3.6-16.1 $\mu \mathrm{m}$, without gaps, and covers the spectral ranges and resolutions of all current and planned advanced high spectral resolution infrared spectrometers to fly on polar orbiting and geostationary weather satellites. The NAST-I spectral resolution $\left(0.25 \mathrm{~cm}^{-1}\right)$ is equal to, in the case of IASI, or higher than all current and planned advanced sounding instruments. The NAST-I spatially scans the Earth and atmosphere from an aircraft, such as the Northrop-Grumman Proteus 
aircraft used here. NAST-I provides a vertical resolution of 1-2 kilometers for atmospheric temperature and water vapor, so that the distinct number of layers observed depends upon aircraft altitude. From an aircraft, the NAST-I provides a field of view size of 130 meters per kilometer of aircraft altitude (e.g., from the Proteus altitude of $16 \mathrm{~km}, 2.0 \mathrm{~km}$ spatial resolution is achieved). Thus, NAST-I provides high spatial resolution three-dimensional hyperspectral images of radiance and derived geophysical products. The NAST-M provides 29 spectral channels in the $50-425 \mathrm{GHz}$ range (i.e., 8 channels in the 50-56 GHz Oxygen band, 7 channels on $118 \mathrm{GHz}$ Oxygen line, 7 channels on the $183 \mathrm{GHz}$ water vapor line, and 7 channels on the 425 Oxygen line). Like NAST-I, NAST-M spatially scans the atmosphere with a ground resolution of $130 \mathrm{~m} / \mathrm{km}$ of flight altitude. NAST-M provides temperature and water vapor sounding information through non-precipitating clouds and maps out the spatial distribution of precipitating cells in the atmosphere. The S-HIS is a Michelson interferometer covering the spectral range of 3.0-17.0 $\mu \mathrm{m}$ and possessing slightly higher spatial resolution $\left(100 \mathrm{~m} / \mathrm{km}\right.$ of flight altitude), but with half the spectral resolution $\left(0.5 \mathrm{~cm}^{-1}\right)$, of the NAST-I. From the Proteus aircraft, the S-HIS is able to view upwards towards cold space as well as to spatially scan the Earth below. The upward sky-view enables accurate in-flight validation of the calibration of the S-HIS which in turn can be used to validate the calibration of the NAST-I. The FIRSC is a two-band nadir pointing Michelson interferometer, which has a spectral resolution of 0.1 $\mathrm{cm}^{-1}$. Band 1 observes the up welling radiation in the $10-47 \mathrm{~cm}^{-1}(300-1400 \mathrm{GHz})$ spectral region while band 2 observes the up welling radiation in the $80-135 \mathrm{~cm}^{-1}(75-135 \mu \mathrm{m})$ region of the spectrum. The main purpose of the FIRSC is to observe the microphysical properties of cirrus clouds using its broad range far-infrared measurement wavelengths, which span the intermediate infrared to microwave region of the spectrum. The MicroMAPS instrument is a nadir-viewing gas filter radiometer that operates in the 4.67-micrometer band of carbon monoxide. The MicroMAPS consists of a gas filter correlated radiometer, which has a rotating wheel with $2 \mathrm{CO}$ and $1 \mathrm{~N}_{2} \mathrm{O}$ channels. The MicroMAPS is a nadir-pointing instrument with a spatial resolution of $52 \mathrm{~m} / \mathrm{km}$ of flight altitude. The Proteus generally maintained a flight altitude in the range of 15 to $17 \mathrm{~km}$, depending upon flight duration, when under flying the Aqua satellite and over flying the IMAA/DIFA ground sites and the FAAM BAe146-301 aircraft measurements.

FAAM BAe146-301 (Met Office and NERC): The FAAM BAe146-301 is jointly funded by the UK Met Office and the Natural Environment Research Council. Capable of operating between $15 \mathrm{~m}$ and $13 \mathrm{~km}$ the aircraft can carry a scientific payload of $4000 \mathrm{~kg}$. For the EAQUATE campaign the scientific payload consisted of a combination of spectrometers for measuring the radiation from the visible through to the microwave region of the electro-magnetic spectrum plus an array of instrumentation to characterize the troposphere both in terms of thermodynamical variables like temperature and water vapor but also particulates in the form of aerosols and cloud particles. The main focus of the work during EAQUATE was cloud free atmospheres but one flight in cirrus clouds was conducted under an AQUA overpass. The BAe146-301 operated a number of radiometer (a) The ARIES instrument operates within the 3.3 to $16 \mu \mathrm{m}$ region with $0.5 \mathrm{~cm}^{-1}$ spectral resolution with both upward and downward-pointing for radiative transfer model validation, temperature profiling and profiling of various species (e.g. water, ozone), cloud and surface emissivity studies, etc. ARIES views range from the zenith, to Earth viewing from nadir $-5^{\circ}$ to nadir $+60^{\circ}$ across track. (b) The Dualfrequency Extension to In-flight Microwave Observing System (DEIMOS) is a scanning microwave radiometer, with four channels (each of two orthogonal polarizations at 23 and $50 \mathrm{GHz}$ ). It performs either upward or downward viewing measurements for satellite inter comparisons, radiative transfer model validation, surface emissivity studies, etc. (c) The Tropospheric Airborne Fourier Transform Spectrometer (TAFTS) (owned by Imperial College, London) operates within the 12.5 to $125 \mu \mathrm{m}$ region with $0.1 \mathrm{~cm}^{-1}$ spectral resolution. (d) The Microwave Airborne Radiometer Scanning System 
(MARSS) operates at AMSU-B channels 16-20 (89 to 183GHz) and scans both upward and downward for satellite inter comparisons, radiative transfer model validation, temperature and humidity profiling, column liquid water retrievals, precipitation, ice cloud and surface emissivity studies, etc. The FAAM BAe146-301 was extensively equipped for studying the in-situ structure of the atmosphere. In addition to temperature, water vapor was measured using a General Eastern chilled mirror hygrometer a Lyman-alpha absorption hygrometer and a fluorescence water vapor sensor. During the EAQUATE flights drop sondes were launched to give vertical profiles of temperature and water vapor. During satellite overpasses up to 14 sondes were launched in quick succession giving high levels of spatial detail. In addition to the thermodynamic measurements the BAe146-301 made continuous measurements of Carbon Monoxide and Ozone concentrations as well as measuring aerosol and cloud particle size, shape and concentration.

Ground-based (IMAA/DIFA/UNINA): A wide range of instrumentation was used during EAQUATE measurement campaign: ground based, airborne and satellite borne.

During the Italian phase of the experiment, the ground based instrumentation was located at three different sites located in Southern Italy. These systems were operated continuously throughout the Proteus airborne measurement period, which included the Aqua overpass times. A short description of the ground based instrumentation, is given below:

The Istituto di Metodologie per l'Analisi Ambientale (IMAA) in Tito Scalo (40³6'4.32'N, $15^{\circ} 43^{\prime} 25.32^{\prime \prime} \mathrm{E}, 760 \mathrm{~m}$ a.s.1.):

- An Aerosol LIDAR system based on a Nd:YAG laser operating on fundamental, second and third harmonics with a repetition rate up to $20 \mathrm{~Hz}$. Aerosol backscatter measurements were performed at both $355 \mathrm{~nm}$ and $532 \mathrm{~nm}$, while aerosol extinction coefficient are retrieved from simultaneous N2 Raman backscatter signals at $386.6 \mathrm{~nm}$ (Matthias et al., 2004).

- A Raman LIDAR system based on an Nd:YAG laser equipped with third harmonic generator $(355 \mathrm{~nm})$ with a repetition rate up to $100 \mathrm{~Hz}$. This system is able to measure water vapor mixing ratio profiles from about $60 \mathrm{~m}$ above lidar station up to the UTLS (upper troposherelower stratosphere) region (Cornacchia et al., 2004).

- An Infrared Interferometer (ABB MR-100) was used to measure sky radiance in the range 500 to $5000 \mathrm{~cm}-1$, with a resolution of $0.5 \mathrm{~cm}-1$. Measured radiances will be inverted in order to obtain water vapor, temperature profiles and information on cloud properties. The interferometer is calibrated by using two blackbodies and it is completely automated. The interferometer aperture is about $45 \mathrm{mrad}$.

- The REFIR/BB (Radiation Explorer in Far Infrared/Bread Board) FTS measuring over the range $100-1050 \mathrm{~cm}-1$ with a resolution of $0.5 \mathrm{~cm}-1$. REFIR/BB is a collaboration between DIFA-University of Basilicata, CNR-IFAC (Istituto di Fisica Applicata) and CNR-IMAA. This far-infrared interferometer is particularly useful for study of the water vapor rotational bands that account for a significant fraction of the atmosphere long wave emission.

- A Radio-sounding system consisting of balloon borne sensors for observing vertical profiles of humidity, temperature and pressure (Vaisala type RS90 and RS92 sondes).

- A 12 channel microwave radiometer providing temperature and water vapor profiles from the surface up to $10 \mathrm{~km}$ in height and low resolution cloud liquid water profiles.

- A VAISALA ceilometer based on a pulsed diode laser lidar technology to detect clouds, precipitation and other obstructions to vision, providing cloud height of first three layers up to $7.5 \mathrm{~km}$ with a resolution of $15 \mathrm{~m}$ at a rate of 5 profiles per minute.

DIFA Potenza $\left(40^{\circ} 38^{\prime} 45.23 ’ \mathrm{~N}, 15^{\circ} 48^{\prime} 29.32^{\prime \prime} \mathrm{E}, 770 \mathrm{~m}\right.$ a.s.1.): 
- A Raman LIDAR system for water vapor and temperature measurements was operational at DIFA in Potenza. This system is based on a Nd:YAG laser operating at $355 \mathrm{~nm}$, with a pulse repetition rate up of $20 \mathrm{~Hz}$. Using Raman/elastic scattering from atmospheric molecules and particles, the system measures high temporal and spatial resolution profiles of particle backscattering and extinction coefficients at $355 \mathrm{~nm}$, water vapour mixing ratio and temperature profiles in daytime and night-time. The DIFA lidar is located in downtown Potenza, approximately $8.3 \mathrm{~km}$ eastward of the Tito Scalo ground site.

UNINA Napoli (4050’18’’N, 14¹0’59’’E, $118 \mathrm{~m}$ a.s.1.):

- A Raman LIDAR system for water vapor and aerosol measurements was operational in Napoli (UNINA). This lidar is based on a Nd:YAG laser source at 355 and 532nm, with a repetition rate of $20 \mathrm{~Hz}$. Data are acquired with a row spatial and temporal resolution of $15 \mathrm{~m}$ and $1 \mathrm{~min}$, respectively. Aerosol backscatter and extinction at $355 \mathrm{~nm}$ are retrieved by using both elastic and Raman echoes, whereas backscatter at $532 \mathrm{~nm}$ is retrieved only through corresponding elastic signal .Furthermore, the Raman signal at 407nm allows to retrieve the water vapour mixing ratio profile. The instrument has been extensively involved in the EARLINET project (Boesenberg, J., et al., 2001). During the EARLINET project, special care was devoted to the validation of the experimental set-up (Matthias et al., 2004) and the algorithms to retrieve aerosol backscattering (Bockmann et al., 2004) and extinction coefficients (Pappalardo et al., 2004)

Aqua $\boldsymbol{A I R S}(\mathrm{NASA})$ : The AIRS instrument flying aboard the EOS Aqua polar orbiting satellite is the first space borne spectrometer designed to meet the $1-\mathrm{K} / 1-\mathrm{km}$ sounding accuracy objective by measuring the infrared spectrum quasi-continuously from 3.7 to 15.4 microns with high spectral resolution $(v / \delta v=1200 / 1)$. The sensitivity requirements, expressed as Noise Equivalent Differential Temperature (NEDT), referred to a $250 \mathrm{~K}$ target-temperature, ranges from $0.1 \mathrm{~K}$ in the $4.2 \mu \mathrm{m}$ lower tropospheric sounding wavelengths to $0.5 \mathrm{~K}$ in the $15 \mu \mathrm{m}$ upper tropospheric and stratospheric sounding spectral region. The AIRS Instrument provides spectral coverage in the $3.74 \mu \mathrm{m}$ to 4.61 $\mu \mathrm{m}, 6.20 \mu \mathrm{m}$ to $8.22 \mu \mathrm{m}$, and $8.8 \mu \mathrm{m}$ to $15.4 \mu \mathrm{m}$ infrared wavebands at a nominal spectral resolution of $v / \delta v=1200$, with 2378 IR spectral samples and four visible/near-infrared (VIS/NIR) channels between 0.41 and 0.94 microns. Cross-track spatial coverage with $\sim 16 \mathrm{~km}$ linear resolution, depending on scan angle, and views of cold space and hot calibration targets are provided by a 360degree rotation of the scan mirror every 2.67 seconds. The AIRS radiance measurement accuracy and its ability to achieve the $1-\mathrm{K} / \mathrm{km}$ sounding accuracy objective are to be validated using the EAQUATE surface and airborne data sets.

\section{The Italian Phase}

The Italian phase of the EAQUATE measurement campaign took place between the $6^{\text {th }}$ and $10^{\text {th }}$ September 2004.

Figure 3 shows the times for all measurements - note that two flights of the Proteus aircraft were coincident with Aqua overpasses. 
The Proteus aircraft flew legs at high altitude along the line of the Aqua overpasses at 0101UTC on $8^{\text {th }}$ September and 0056UTC on $10^{\text {th }}$ September (Figure 4). The numbers of overpasses of the ground sites by the Proteus aircraft are given in the figures.

\section{a. NAST-I, AIRS Retrieval Validation}

The NAST-I instrument on Proteus covers the entire spectral range of AIRS at greater resolution allowing direct comparison of radiances and of level 2 products like temperature and water vapor. During the night of September 9-10, 2004 the Proteus aircraft flew a flight track over Southern Italy coincident with the AIRS overpass at 00:56 UTC of September 10. The aircraft track passed over the Potenza site allowing a direct comparison of the satellite, aircraft, and ground based profile information. The NAST team of scientists has developed an inversion scheme. Detailed NAST-I physically-based EOF (i.e., Empirical Orthogonal Function) regression and simultaneous matrix inversion (i.e., non-linear multi-variable physical iteration) can be found in Zhou et al. (2002). NAST-I measurements and its inversion algorithm have been validated through numerous dedicated field experiments (e.g., Smith et al. 2005). Processing AIRS data and NAST-I data through this inversion scheme allows the inter-comparison of thermodynamic parameters.

AIRS original single field of view (FOV) radiances are put through the NAST-team inversion scheme to produce AIRS retrievals to compare with the NAST-I retrievals degraded to AIRS full spatial resolution (i.e., AIRS single FOV). The same inversion algorithm is applied to both AIRS and NAST-I data to minimize the impact of inversion algorithm differences on the retrieval products. However, it should be noted that the forward radiative transfer models used differ in that the Stand-alone AIRS Radiative Transfer Algorithm (SARTA) (Strow et al., 2004) is used for the AIRS retrieval while the Optimal Spectral Sampling (OSS) fast molecular radiative transfer model (Moncet et al. 2003; Liu et al. 2003) is used for the NAST-I retrieval. These retrievals can then be compared directly with the measurements of dedicated radiosonde and Raman Lidar (e.g., Cuomo et al. 2004; Di Girolamo et al., 2004; Di Girolamo et al., 2006). Under cloud-free conditions, the retrieved effective surface skin temperature is equivalent to the skin temperature. Figure 5 shows the skin temperature retrieved from AIRS and NAST-I with a full spatial resolution of $\sim 16 \mathrm{~km}$ and $\sim 2$ $\mathrm{km}$, respectively. Profiles of temperature and moisture retrieved from AIRS and NAST-I are validated with dedicated radiosonde and Raman Lidar observations during the EAQUATE. In the figure, the lines with arrows indicate the Aqua and Proteus flight directions with associated time. The open cycles represent AIRS single FOV within NAST-I ground track swath width.

The mean profile of the section shown in Figure 5 (indicated with the open cycles) is plotted in Figure 6 with a Vaisala-type radiosonde and 2 Raman Lidar observations from Potenza. One Raman Lidar station (labeled Lidar \#1) is located at Potenza (latitude of $40^{\circ} 39^{\prime} \mathrm{N}$, longitude of $15^{\circ} 48^{\prime} \mathrm{E}, 730$ $\mathrm{m}$ above sea level) while another Raman Lidar station (labeled Lidar \#2) and a radiosonde station are located at Tito Scalo, Potenza (latitude of $40^{\circ} 36^{\prime} \mathrm{N}$, longitude of $15^{\circ} 44^{\prime} \mathrm{E}, 760 \mathrm{~m}$ above sea level). A dedicated radiosonde was launched while Proteus was passing over Potenza. The Raman Lidar data were extensively processed (i.e., a 10-minute integration time and variable vertical averaging) in order to reach a higher altitude for retrieval validation as Aqua and Proteus were passing over. The

Raman Lidar data plotted in

Figure 6 are the mean profiles of Aqua (00:56 UTC) and Proteus (00:37 UTC) overpasses. The retrievals from both AIRS and NAST-I compare favorably to Raman Lidar and radiosonde 
observations. However, a few noticeable features are included as (1) the integration time difference between AIRS and NAST-I, in other words, the Aqua satellite passed over quickly while the Proteus's flight from south to north took more than one hour, (2) the averaged profile reduced vertical resolution of a single FOV retrieval has a lower vertical resolution (approximately 2-3 km) while radiosonde and Raman Lidar observations have a much higher vertical resolution (15-500 m depending on altitude), (3) a dry bias in the humidity measurement from a Vaisala-type radiosonde at altitudes above $\sim 8 \mathrm{~km}$ has been noticed here as well as in other validations, and (4) the fine vertical structures (i.e., resolution) of the retrieved profiles are partially due to the instrumentation characters such as the spectral resolution and instrument noise, which could cause a difference in the profile. Overall, the retrievals from the 2 different sounders compare favorably with each other. The difference of the section means is plotted within the uncertainty of retrieved products. This implies that both instruments are well calibrated and the radiative transfer models are equivalently accurate.

\section{b. NAST-I Retrieval Over Land}

One of the NAST-I footprints at 00:32UTC on 10th September was over a small tree covered hill close to the IMAA/CNR Institute. The emissivity of the surface, which was covered by conifer trees, was determined from fitting a set of 16 clear sky spectra recorded by NAST-I. A physical retrieval scheme using the $\sigma$-IASI code (Amato et al, 2002; Carissimo et al, 2005) has been used to retrieve temperature (Figure 7) and water vapor profiles (Figure 8). The physical retrieval scheme can be run using either two or three spectral bands. The 2 spectral band option uses bands between $670-830 \mathrm{~cm}^{-1}$ and $1100-1200 \mathrm{~cm}^{-1}$. The 3 band option uses an additional band $1450-1600 \mathrm{~cm}^{-1}$. The 3 band option includes a portion of the water vapor vibrational band at $6.7 \mu \mathrm{m}$. The inclusion of this band has negligible impact on the temperature retrieval but increases the amount of retrieved water vapor in the lower atmosphere.

\section{c. Combining Ground-based RAMAN Lidar and NAST-I Airborne Spectrometer to Describe the Evolution of a Cirrus Cloud.}

The data analyzed refer to the second day of measurements of the Italian campaign $\left(6^{\text {th }}\right.$ September) when the Proteus aircraft flew four times over a high cirrus cloud in the Potenza region. The cloud evolution was monitored by the DIFA Raman lidar ground station in Potenza by measuring particle backscatter and extinction at $355 \mathrm{~nm}$. The Raman lidar system also measured the water vapor mixing ratio and atmospheric temperature profiles, with accurate information of the statistical measurement uncertainty so that large uncertainties of the lidar-measured parameters could easily be identified and excluded from further interpretations. Lidar measurements were acquired with a maximum temporal and vertical resolution of $1 \mathrm{~min}$ and $30 \mathrm{~m}$, respectively. Three radiosondes were released from the IMAA ground station (Tito Scalo - Potenza) in 4 hours, and the description of the time evolution of the atmospheric temperature profile and of the atmospheric gaseous and particulate state is therefore excellent.

The objectives of the study were: 1) to co-locate and jointly process data measured by a range of different sensors (Radiosondes/Raman-lidar/NAST-I interferometer); 2) to evaluate the relevance of the lidar information in clear and cloudy sky conditions; 3) to simulate NAST-I data at different viewing angles and investigate the consistency between measured and modeled radiances in presence of ice clouds; 4) to determine the temporal sequence of the cooling rate profiles and evaluate the importance of the combined lidar-spectrometer information in predicting the evolution 
of a cirrus cloud and 5) to set the basis for a study of the evolution of the cirrus cloud accounting for the dynamics and microphysics.

The radiosonde temperature profile is used to characterize the atmosphere below flight level during the 4 overpasses. The water vapor mixing ratio profile, obtained from the lidar measurements, is used when the associated percentage error is less than 50\% while radiosonde data are used to fill the lidar blind region ( $60 \mathrm{~m}$ above the lidar) and the lidar data affected by large uncertainties.

The NAST-I radiances measured during the 4 overpasses and the DIFA lidar data indicate the presence of a high cirrus cloud whose optical depth is decreasing from the first to the fourth overpass. Lidar backscatter data places cloud top at about $10 \mathrm{~km}$ of altitude above the DIFA site, as indicated in Table 1 that contains a summary of the main features of the cirrus cloud in correspondence to the 4 Proteus overpasses over Potenza.

Line-by-line computations of molecular optical depths are performed using HARTCODE (Rizzi, Matricardi and Miskolczi, 2002). Single scattering properties for the cloud layers are generated assuming that ice particles are hexagonal columns (Fu et al., 1997; Fu et al., 1998). The cloud optical depths, altitudes and geometrical thickness for the 4 overpasses are determined by the lidar measurements of extinction and backscattering coefficients. The radiative transfer calculations are based on the adding and doubling method to handle multiple scattering conditions (Evans and Stephens, 1991; Rizzi et al., 2001) and the high spectral resolution radiances are convolved with the NAST-I instrument function.

Since the differences in brightness temperature (BT) between NAST-I and simulations are less then $4 \%$, for all four overpasses, fluxes and heating rates have been computed at all levels at resolution of $0.05 \mathrm{~cm}-1$ for each NAST-I overpass of the Potenza region. The results for the total cooling rates are shown in Figure 9. The main preliminary conclusions are that a) lidar-derived parameters are fundamental in distributing the IWC inside the cloud depth and thus in determining the cooling rates and layers' energy balance, and b) the radiative energy exchange does not explain the whole ice cloud sublimation and microphysics and dynamics need to be accounted for an exhaustive study of a cloud evolution.

The time evolution of the cirrus cloud has also been followed and analysed with BOMEM MR-100 FTS spectral observations. The spectral radiance was almost continuously recorded for the same day as above (6th September) from 17:00 until 19:00. The cloud transmittance can be derived with some accuracy from the spectral radiance in the ozone band (1000-1100 cm-1), by a technique implemented at DIFA (R. Restieri, 2006).

In this approach stratospheric ozone is treated as a source (above the cloud level), whose emission is attenuated, with respect to clear sky, by the presence of the cloud. The transparency of the sky can be then computed by contrasting clear sky observations against those for cloudy-sky and considering a simplified radiative transfer through the atmosphere. The simplification includes the assumptions that a) the ozone content does not change during the measurements and that the radiance contribution by tropospheric ozone is negligible; b) the spectral radiance is formed basically by the sky radiance, supposed to contribute with a continuum term, and by the ozone emission. With this assumptions the spectral radiance, $L(v)$ at wave number, $v$ can be written, for a spectral region which includes the $\mathrm{O}_{3}$ absorption band at $9.6 \mu \mathrm{m}$, as 
$L_{c l r}(v)=L_{C}(v)+L_{O_{3}}(v) T_{c l r}(v)$

for clear sky, and

$L_{c l d}(v)=L_{C}^{\prime}(v)+L_{O_{3}}(v) T_{c l r}(v) T_{c l d}(v)$

for cloudy sky. In these two formulas, the under scripts clr and cld stand for clear and cloudy sky, respectively; $L_{C}$ and $L_{C}^{\prime}$ represent the background continuum contribution from the sky, $L_{O_{3}}$ is the ozone emission and $T$ is the atmospheric transmittance.

The continuum contribution can be estimated by a proper polynomial fitting to the observations in a spectral region which includes also the far wing of the ozone band. Having done that, it can be subtracted from the observed radiance to obtain the cloudy transmittance,

$T_{c l d}=\frac{L_{c l d}(v)-L_{C}^{\prime}(v)}{L_{c l r}(v)-L_{C}(v)}$

The calculation of the background continuum is outlined in Figure 10 (left). The evolution of the cloud transmittance is shown in the same figure (right). This time evolution agrees with the evolution seen by the Raman Lidar.

\section{The UK Phase}

During the UK phase of EAQUATE the Proteus aircraft worked in close collaboration with the BAe146-301 studying the atmosphere during two AIRS overpass days. Flights were flown on the $14^{\text {th }}$ and $18^{\text {th }}$ September 2004. During this phase of EAQUATE the aim was to validate AIRS in the remote marine environment under cloud free conditions by stacking the AIRS satellite, Proteus aircraft and BAe146-301 aircraft vertically over each other during the overpass as indicated in Figure 11. The Proteus aircraft was operating the NAST-I and S-HIS interferometers whilst the BAe146-301 made measurements of the in-situ state of the troposphere and the surface; dropsondes were also launched to more finely characterize the atmospheric column.

The conditions on the 14th September 2004 are clearly shown in the MODIS image in Figure 12. After transiting to the operating area the BAe146-301 conducted a profile descent to an altitude of $15 \mathrm{~m}$ above the sea surface in the area of interest and then flew a straight and level run at $30 \mathrm{~m}$ along the line of the sub-satellite track to measure the sea surface temperature. During this low level run of the BAe146-301 the Proteus aircraft flew at an altitude of around 14km along the same track in the same direction. The ground speed of the BAe146-301 and Proteus were perfectly matched during this run and both aircraft remained stacked above each other for this run. Having characterized the sea surface the BAe146-301 profiled to $8.5 \mathrm{~km}$ and flew backwards and forwards along the sub-satellite track launching drop sondes en-route. Having burnt a bit more fuel the BAe146 was then able to climb to an altitude of $10.6 \mathrm{~km}$ continuing along the sub-satellite track. During all these high level runs the BAe146 made measurements with the ARIES interferometer and its other radiometers. Finally the BAe146-301 conducted a long descending profile back to the 
surface to get a final look at the tropospheric structure of temperature, water vapor, ozone, carbon monoxide and clouds.

The evaluation of satellite data can be conducted in terms of retrieval performance but also importantly in terms of direct radiance validation. The Proteus aircraft flies at an altitude that puts it above most of the atmosphere and hence it is ideally suited for the important job of direct radiance validation using the NAST-I and S-HIS instruments. NAST-I and S-HIS have been compared on many occasions before and their calibration is well characterized. During the EAQUATE campaign the BAe146 and Proteus on occasion both operated at $8.5 \mathrm{~km}$ allowing a direct comparison of NAST-I, S-HIS and ARIES, these data are not shown here for brevity.

\section{a. NAST-I, S-HIS and AIRS Radiance Intercomparison}

Figure 13 shows an intercomparison of the NAST-I, S-HIS and AIRS radiances in 4 different spectral regions during the overpass on the $14^{\text {th }}$ September 2004 . As can be seen the level of agreement between the three instruments is excellent. The larger difference between NAST-I and AIRS in the lower left figure is due to the increased ozone in the atmospheric path seen by AIRS compared to the airborne radiometers.

\section{b. Spatial Variability of Water Vapor and the Importance of In-Situ Measurements.}

The flight of 18th September 2004 saw the BAe146-301 and Proteus aircraft flying together under an AIRS overpass that occurred at 12:54. The Proteus flew at a pressure of $150 \mathrm{hPa}$ whilst the BAe146 operated at around $350 \mathrm{hPa}$. Whilst the Proteus aircraft flew a series of runs up and down a track measuring the upwelling radiances with its range of spectrometers the BAe146 flew along the same track launching a series of 9 drop sondes to characterize the temperature and water vapor structure of the troposphere. This data set is being used to evaluate the performance of the NASTI retrieval scheme which is in turn being used to validate the AIRS instrument retrieval. In addition to this validation study the data set allows a study of the horizontal variability of the thermodynamic structures in the atmosphere which are important to understand when considering cal/val of satellite instruments. Figure 14 shows the positions of NAST-I nadir view retrievals of temperature and water vapor between 12:21:00 and 13:08:53 ( a total of 208 retrievals) where the data has been filtered to remove points with aircraft roll in excess of 10 degrees.

The times of the drop sondes were 12:52, 12:55, 12:58, 13:01, 13:03, 13:12, 13:15, 13:19 and 13:50 so are all within 30 minutes of the NAST-I retrievals with many of them being significantly closer in time. To give an idea of scale the horizontal distance from the launch to splash down position of the most northern drop sonde shown in Figure 14 is $10.97 \mathrm{~km}$. Understanding spatial variability in water vapor and temperature fields is critical to the interpretation of remote sensing data and any data used in a validation exercise - here NAST-I retrievals will be used for this purpose. For each pressure level of the retrievals the absolute value of the relative humidity difference between adjacent retrieval pixels $(1.75 \mathrm{~km})$ have been computed and the average taken. There were 208 retrievals in all so for 1 pixel difference 207 humidity differences are available for each pressure level. This exercise was carried out again looking at the differences for all possible 2 pixel differences (equivalent to spatial scales of around $3.5 \mathrm{~km}$ ) through to all possible 50 pixel differences 
(equivalent to spatial scales of around $105 \mathrm{~km}$ ). Figure 15 shows, as a contour plot, the average difference in relative humidity, evaluated from NAST-I retrievals, as a function of pressure and the horizontal scale. For high levels in the atmosphere (above $700 \mathrm{hPa}$ ) the variability of water vapor is low and hence for all scales evaluated up to $105 \mathrm{~km}$ the relative humidity difference does not vary from one sounding to another above about 3\% (absolute $\mathrm{RH}$ ). At lower levels around $800 \mathrm{hPa}$ the humidity differences grow to nearer $6 \%$ for distances in excess of $40 \mathrm{~km}$. In the boundary layer the story is totally different, the weather on this day consisted of a high pressure system with dry air aloft and a moist boundary layer between the surface and around $875 \mathrm{hPa}$. The data from the retrievals in the boundary layer show that the variability in relative humidity grows with horizontal distance. It is hoped that IR sounders like AIRS and future sounders like IASI and CrIS will be able to allow retrieval of relative humidity to within $10 \%$ over a $1 \mathrm{~km}$ thick layer. This analysis suggests that to evaluate a retrieval to this level of accuracy will require in-situ truth measurements from within $\sim 10 \mathrm{~km}$ of the retrieval. Clearly the horizontal scales of importance will differ from day-today with the prevailing meteorological conditions and also with the horizontal averaging of the remote sensing instrument. However, this analysis is indicative of the importance of gaining high quality and spatially correlated in-situ data as was available during the EAQUATE campaign.

Figure 16 shows the 9 drop sonde profiles of temperature (red lines), the AIRS retrievals from the 6 pixels in the geographic region of Figure 14 (blue lines) and the 208 retrievals of temperature from NAST-I (black crosses). The AIRS retrievals are Version 3 Level 2 product 3x3 FOV averages with a spatial scale of $45 \mathrm{~km}$. Figure 17 shows the profiles of relative humidity in the same way. Several features are apparent, the NAST-I retrievals of temperature differ from the dropsondes the most around the 750 to $800 \mathrm{hPa}$ area which is where the relative humidity is changing most rapidly. Furthermore the NAST-I and AIRS retrievals of relative humidity are generally too moist in the boundary layer.

Figure 18 shows the difference in temperature retrievals whilst Figure 19 shows the difference in relative humidity. The differences are defined as retrieval minus sonde. Prior to computing the difference the profile of each dropsonde was re-sampled to the respective pressure levels of the two retrievals (AIRS and NAST-I). This was done by taking the average of the sonde data over the respective model layers. The NAST-I retrieval product is defined at 32 levels in the troposphere below the altitude of the BAe146 (which launched the drop sondes) whereas the AIRS retrieval is only defined at 7 levels in this region.

Considering first the temperature differences; generally throughout the troposphere both NAST-I and AIRS give retrieved profiles that are within $1 \mathrm{~K}$ of the drop sonde data. The main exception being NAST-I retrievals which are of the order of $-1.8 \mathrm{~K}$ around $750 \mathrm{hPa}$. It should be noted however that the coarser resolution of the AIRS retrievals means that this instruments is unable to resolve the sharp boundary layer structure of this day. The relative humidity differences show that both AIRS and NAST-I retrievals perform worst in the boundary layer with differences of $\sim 20 \%$ and $\sim 10 \%$ for NAST-I and AIRS respectively. Apart from the deviations in the boundary layer both retrievals are within $10 \%$ of the drop sonde data with the NAST-I retrieval performing best in the upper troposphere.

\section{c. Validation of AIRS Level 2 Products.}


The BAe146 can be flown in profiles down to an altitude of $15 \mathrm{~m}$ over the sea surface and in straight and level flight at $30 \mathrm{~m}$ for prolonged periods. This allows the surface to be characterized in some detail. During the flight on the 18th September 2004 a long run was flown at 30m immediately preceding the satellite overpass. The BAe146 can measure the sea surface temperature with its Heimann radiometer and with the ARIES instrument. During this run the ARIES instrument was mainly used to look up through the atmosphere but for a short time looked at the surface in order to provide a calibration check of the Heimann instrument. The Heimann instrument is stable but its absolute accuracy is not as good as the ARIES instrument; therefore the ARIES data act as a quality control and have been used to calibrate the Heimann observations.

Figure 20 shows the BAe146 data and the AIRS Level 2 product using version 4 of the retrieval algorithm [unofficial, courtesy C. Barnet at NOAA]. Neighboring AIRS fields of view (FOVs) have been interpolated to estimate the satellite-derived SST coincident with the aircraft measurements. The area of operations was fairly close to the UK mainland and hence is subject to significant gradients in sea surface temperature. At the northern end of the run both the ARIES and Heimann instruments showed the same gradient of SST with distance which is indicative of the response of the two instruments being the same.

Figure 21 shows the same data displayed as a contour plot, which shows more clearly the spatial variability of the SST on this day as measured by AIRS. It is apparent from Figure 20 and Figure 21 that the AIRS Level 2 SST is significantly lower than that measured by the BAe146 across the run, with a discrepancy of $0.0-0.5 \mathrm{~K}$ at the northern end and $0.6-1.5 \mathrm{~K}$ at the southern end. These differences mostly exceed the expected ARIES retrieval accuracy of $\pm 0.2 \mathrm{~K}$.

\section{Conclusions}

The EAQUATE campaign brought together an extensive range of airborne and ground based observing systems to provide validation of AIRS level 1 and 2 products. The campaign focused on the provision of high quality radiance spectra from the NAST-I and S-HIS interferometers on the Proteus aircraft backed up with detailed measurements of the tropospheric temperature and water vapor structure. During the Italian phase of the campaign a network of ground based lidar systems provided the detail of the tropospheric water vapor structure at high temporal resolution. During the UK phase of the campaign detailed measurements of the atmosphere over the marine environment was provided by the extensively equipped FAAM BAe146-301 aircraft - a critical element of this was the use of multiple dropsondes.

The radiance performance of satellite instruments like AIRS can be evaluated through direct comparison with higher spectral resolution instruments like NAST-I and S-HIS which are resampled spectrally and spatially to the AIRS specification. Analysis here shows excellent agreement between the instruments. During the UK phase of the campaign the airborne interferometers on the BAe146-301 and Proteus were directly compared during a wing tip to wing tip intercomparison run which gives confidence in the radiometric performance of the airborne interferometers.

Working from this position of confidence in the direct radiometric performance of the various instruments the data gathered during EAQUATE have been used to evaluate the range of level 2 products derived from AIRS. This has been done through direct comparison with similar level 2 
products from the airborne interferometers (NAST-I and S-HIS) and through comparison with lidar and dropsonde profiles. Comparison of retrievals during the Italian and UK phases of EAQUATE have shown that mostly the $1 \mathrm{~K}$ and $10 \%$ accuracy required for temperature and humidity is being met by AIRS. Comparison of level 2 sea surface temperature data from AIRS with airborne radiometers shows discrepancies between 0.0 and $1.5 \mathrm{~K}$ which exceeds the expected accuracy of $+/-$ $0.2 \mathrm{~K}$.

The EAQUATE campaign has shown the critical importance of coordinated measurements by a range of observing systems. Over the marine environment coordinated operations between high altitude and tropospheric aircraft are critical in satellite cal/val. In particular due to the high variability of water vapor in the atmosphere a high density of colocated drop sondes within $10 \mathrm{~km}$ of the retrieval footprint are required for a useful assessment to be made of the retrieval performance.

In late 2006 IASI will be launched on the METOP platform and this will be followed by CrIS on the NPP/NPOESS platform in 2009. Calibration and validation of these instruments will be vital in order that the maximum benefit can be realized for numerical weather prediction. Calibration/validation of IASI is planned for the spring of 2007 using the FAAM BAe146-301 aircraft and the NASA WB-57 aircraft which will carry the NAST-I and S-HIS interferometers. This campaign will include measurements over the remote marine environment and over the ARM Great Plains site in Oklahoma. Lessons learnt during EAQUATE will allow for the optimization of data gathering and analysis.

\section{Acknowledgments}

The FAAM BAe146-301 is jointly funded by the Met Office and the Natural Environment Research Council. 


\section{References}

Amato, U., G. Masiello, C. Serio, and M. Viaggiano, 2002: The $\sigma$-IASI code for the calculation of infrared atmospheric radiance and its derivatives. Environmental Modelling \& Software, 17, 651667.

Amorati, R., and R. Rizzi, 2001: Simulated radiances in presence of clouds using a fast radiative transfer model and a full scattering scheme. Appl. Opt., 41(9), 1604-1614.

Böckmann, C. et al., Aerosol lidar intercomparison in the framework of the EARLINET project. 2. Aerosol backscatter algorithms, Appl. Opt., 43, 977-989, 2004.

Boesenberg, J., et al. EARLINET: A European Aerosol Research Lidar Network, in: Advanced in Laser Remote Sensing, pp.155-158, Dabas, A., Loth, C., and Pelon, J., (Eds.), 2001.

Carissimo, A., I. De Feis and C. Serio, 2005, The physical retrieval methodology for IASI: the $\delta$ IASI code. Environmental Modelling \& Software, 20, 1111-1126.

Cornacchia C., A. Amodeo, L. Mona, M. Pandolfi, G. Pappalardo, V. Cuomo, 2004: The IMAA Raman lidar system for water vapor measurements. Reviewed and Revised Papers presented at the $22^{\text {nd }}$ International Laser Radar Conference, G. Pappalardo and A. Amodeo Editors, ESA SP-561, 107-110, Matera, Italy,.

Cuomo V., A. Amodeo, C. Cornacchia, L. Mona, M. Pandolfi, G. Pappalardo, 2004: Envisat validation campaign at IMAA-CNR, Proceedings of the Second Validation Workshop on the Atmospheric Chemistry Validation of ENVISAT (ACVE-2) ESA SP-532, Frascati, Italy,

Di Girolamo, P., R. Marchese, D. N. Whiteman, and B. B. Demoz, 2004: Rotational Raman Lidar measurements of atmospheric temperature in the UV, Geophys. Res. Lett., 31, L01106, doi:10.1029/2003GL018342.

Di Girolamo, P., A. Behrendt, and V. Wulfmeyer, 2006: Spaceborne profiling of atmospheric temperature and particle extinction with pure rotational Raman lidar and of relative humidity in combination with differential absorption lidar: performance simulations, App. Opt. 45, in press.

Evans K. F. and G. L. Stephens, A new polarized atmospheric radiative transfer model, J. Quant. Spectros. Radiat. Transfer, 46, 412-423, 1991.

Fu Q., K. N. Liou, M. C. Cribb, T. P. Charlock, and A. Grossman, 1997, Multiple scattering parameterization in thermal infrared radiative transfer, J. Atmos. Sci., 54, 2799-2812.

Fu Q., Yang Ping, and W. B. Sun, 1998, An accurate parameterization of the infrared radiative properties of cirrus clouds for climate models, J. Clim., 11, 2223-2237.

Liu, X., J.-L. Moncet, D. K. Zhou, and W. L. Smith, 2003: A Fast and Accurate Forward Model for NAST-I Instrument, in Fourier Transform Spectroscopy and Optical Remote Sensing of 
Atmosphere, 2003 Technical Digest Series OSA (Optical Society of America, Washington, D.C., 2003), p. 16.

Madonna F., D’Amico G., Amodeo A., Cornacchia C., Mona L., Pandolfi M., Pappalardo G., and Cuomo V., "Multi-channel microwave radiometer and water vapor raman lidar: comparisons and synergies", AIT INFORMA, Special-issue AIT-CeTeM (in press).

Matthias, V. et al., 2004 "Aerosol lidar intercomparison in the framework of the EARLINET project. 1. Instruments”, Appl. Opt., 43, 961-976,.

Moncet, J. L., and Coauthors, 2003: Algorithm theoretical basis document (ATBD) for the Cross Track Infrared Sounder (CrIS) environmental data records (EDR), V1.2.3, AER Document Number P882-TR-E-1.2.3-ATBD-03-01.

Palchetti L., Bianchini G., Castagnoli F., Carli B., Serio C., Esposito F., Cuomo V., Rizzi R., and Maestri T.2005: Breadboard of a Fourier transform spectrometer for the Radiation Explorer in the Far Infrared atmospheric mission., Appl. Opt. 44, N.14, 2870-2878.

Pappalardo, G., et al., 2004Aerosol lidar intercomparison in the framework of the EARLINET project. 3. Raman lidar algorithm for aerosol extinction, backscatter and lidar ratio, Appl. Opt.,43, 5370-5385,.

Pappalardo G., A. Amodeo, L. Mona, M. Pandolfi, N. Pergola, V. Cuomo, 2004: Raman lidar observations of aerosol emitted during the 2002 Etna eruption. Geophys. Res. Lett., 31, L05120, doi:10.1029/2003GL019073.

Restieri, R., 2006, Retrieval of atmospheric temperature and water vapor profiles from ground based FTS, Phd Thesis

Rizzi R., J. A. Smith, P. di Pietro and G. Loffredo, 2001: Comparison of modelled and measured stratus cloud infrared spectral signatures, J. Geophysical Research, 106, D-24, 34109-34120.

Rizzi R., M. Matricardi and F. Miskolczi, 2002: On the simulation of up-looking and down-looking high-resolution radiance spectra using two different radiative transfer models, Appl. Opt., 41, 940956.

Smith, W. L., D. K. Zhou, A. M. Larar, S. A. Mango, H. B. Howell, R. O. Knuteson, H. E, Revercomb, and W. L. Smith Jr., 2005: The NPOESS Airborne Sounding Testbed Interferometer remotely sensed surface and atmospheric conditions during CLAMS, J. Atmos. Sci., 62, 1117-1133.

Strow, L. L., S. E. Hannon, M. Weiler, K. Overoye, 2003: Prelaunch and in-flight radiometric calibration of the Atmospheric Infrared Sounder (AIRS), IEEE Trans. Geosci. Remote Sensing, 41, 274-286.

Zhou, D. K., W. L. Smith, J. Li, H. B. Howell, G. W. Cantwell, A. M. Larar, R. O. Knuteson, D. C. Tobin, H. E. Revercomb, and S. A. Mango, 2002: Thermodynamic product retrieval methodology for NAST-I and validation, App. Opt., 41, 6957-6967. 


\section{Table Captions.}

Table 1 Main features of the cloud as measured by the DIFA Raman lidar

\section{Figure Captions.}

Figure 1the Proteus Aircraft showing instrumentation fitted during EAQUATE

Figure 2 the FAAM BAe146-301 aircraft showing instrumentation.

Figure 3 Chart showing times of measurements for all instruments involved in the Italian phase of EAQUATE.

Figure 4 AQUA tracks for overnight on the 7th/8th September (a) and overnight on the 9th /10th September (b) and the four Proteus flight tracks (c, d, e and f). The black circles indicate the positions of Napoli, Tito Scalo and Potenza showing that the Proteus over flew each of these sites on every flight.

Figure 5 AIRS and NAST-I retrieved effective surface skin temperature $(\mathrm{K})$ during the night of September 9-10, 2004 (see text).

Figure 6 Retrievals of temperature (upper panel) and relative humidity (lower panel) using AIRS and NAST-I data processed through the NAST-team inversion scheme. Radiosonde and Raman Lidar profiles from Potenza (Ptz) are plotted as references

Figure 7 Temperature retrieval over tree covered land near Tito Scalo on 10th September. First guess shown as black solid line with radiosonde shown as blue curve. The results of the physical retrieval conducted on NAST-I data using the 2 and 3 band scheme are shown in red circles and green crosses (respectively).

Figure 8 Profiles of water vapor mixing ratio. Key to lines and symbols as per Figure 7.

Figure 9 Total infrared heating rates (K/day) corresponding to the 4 Proteus overpasses of the DIFA lidar base.

Figure 10 Analysis of the evolution of the cirrus cloud on 6th September by ground-based spectral observations (ABB MR-100) Left: example of atmospheric radiances measured in clear sky (red) and cloudy sky (blue) together with the fitted back-ground continuum term. Right: Evolution of the cloud transmittance as derived directly from the observations.

Figure 11 Schematic of aircraft operations during the UK Phase of EAQUATE.

Figure 12 The sub-satellite track (top left), BAe146-301 track (bottom right) and BAe146-301 altitude time series (bottom left) overlaid on the Aqua MODIS image for 13:20Z 14th Sept. 2004 The portion of the sub-satellite track studied during this flight is shown as the red line.

Figure 13 Intercomparison of radiances measured by NAST-I (red line), S-HIS (green line) and AIRS (cyan line). 
Figure 14 The position of the NAST-I nadir retrievals (black line) and the launch and splash down positions of the 9 drop sondes (red). Launch points are those to the west.

Figure 15 Contour plot of the average difference in relative humidity from NAST-I retrievals as a function of pressure and horizontal spatial scale.

Figure 16 Profiles of temperature from the 9 drop sondes (red), the 6 AIRS pixels in the region (blue) and the 208 NAST-I retrievals (black crosses).

Figure 17 Profiles of relative humidity from the 9 drop sondes (red), the 6 AIRS pixels in the region (blue) and the 208 NAST-I retrievals (black crosses).

Figure 18 Profile of temperature difference (retrieval minus sonde). The solid line is the difference between the average of all NAST-I retrievals and the average of all 9 drop sondes. The dotted line is the average difference between sonde and NAST-I retrieval where each retrieval has been differenced from its closest sonde in distance. The dashed line is the difference between the average of all 6 AIRS retrievals and the average of all sondes.

Figure 19 Profile of relative humidity difference (retrieval minus sonde). The solid line is the difference between the average of all NAST-I retrievals and the average of all 9 drop sondes. The dotted line is the average difference between sonde and NAST-I retrieval where each retrieval has been differenced from its closest sonde in distance. The dashed line is the difference between the average of all 6 AIRS retrievals and the average of all sondes.

Figure 20 Sea Surface Temperature measured by the BAe146-301 on the 18th September 2004. Measurements with a Heimann radiometer are shown as the crosses (highest values), from the ARIES instrument as black circles and from the AIRS Level 2 processing as the solid line (lowest values). The color scale is the same as that shown in Figure 21

Figure 21 A contour plot of the AIRS Level 2 Sea Surface Temperature product (labeled contours) overlaid with the SST measured from the BAe146-301 during a run at 30m under the sub-satellite track (same color scale). The aircraft run extends from coordinates $(-6.2,50.4)$ to $(-6.8,51.6)$. 


\begin{tabular}{|c|c|c|c|c|c|}
\hline $\begin{array}{c}\text { Overpass } \\
\text { \# (GMT [hh:mm]) }\end{array}$ & $\begin{array}{c}\text { Lowest cloud } \\
\text { Limit [km] }\end{array}$ & $\begin{array}{c}\text { Upper cloud } \\
\text { Limit [km] }\end{array}$ & $\begin{array}{c}\# \\
\text { of layers }\end{array}$ & $\begin{array}{c}\text { Total Optical (Up/Down) } \\
\text { Depth at 355 nm }\end{array}$ & $\begin{array}{c}\text { Simulated Infrared } \\
\text { Transmis. }\left(\mathbf{9 0 0} \mathbf{~ c m}^{-1} \text { ) }\right.\end{array}$ \\
\hline $1(18: 02)$ & 6.505 & 10.065 & 2 & $2.45(1.44 / 1.01)$ & 0.30 \\
\hline $2(18: 20)$ & 6.710 & 10.020 & 2 & $0.57(0.52 / 0.05)$ & 0.75 \\
\hline $3(19: 20)$ & 8.450 & 10.020 & 2 & $0.087(0.073 / 0.014)$ & 0.96 \\
\hline $4(19: 40)$ & 8.380 & 9.230 & 1 & 0.0019 & 0.999 \\
\hline
\end{tabular}




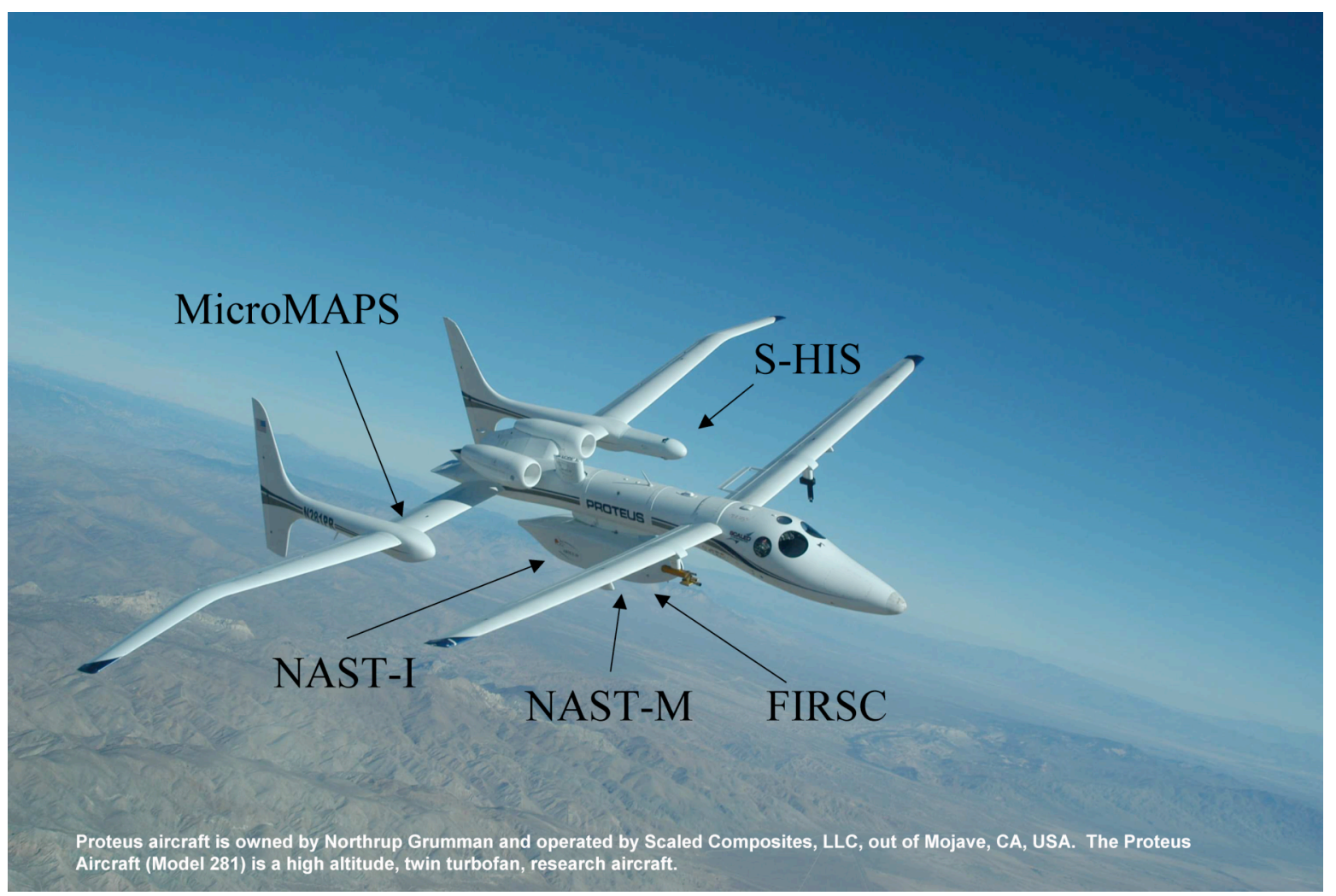

Figure 1

Page 21 of 41 


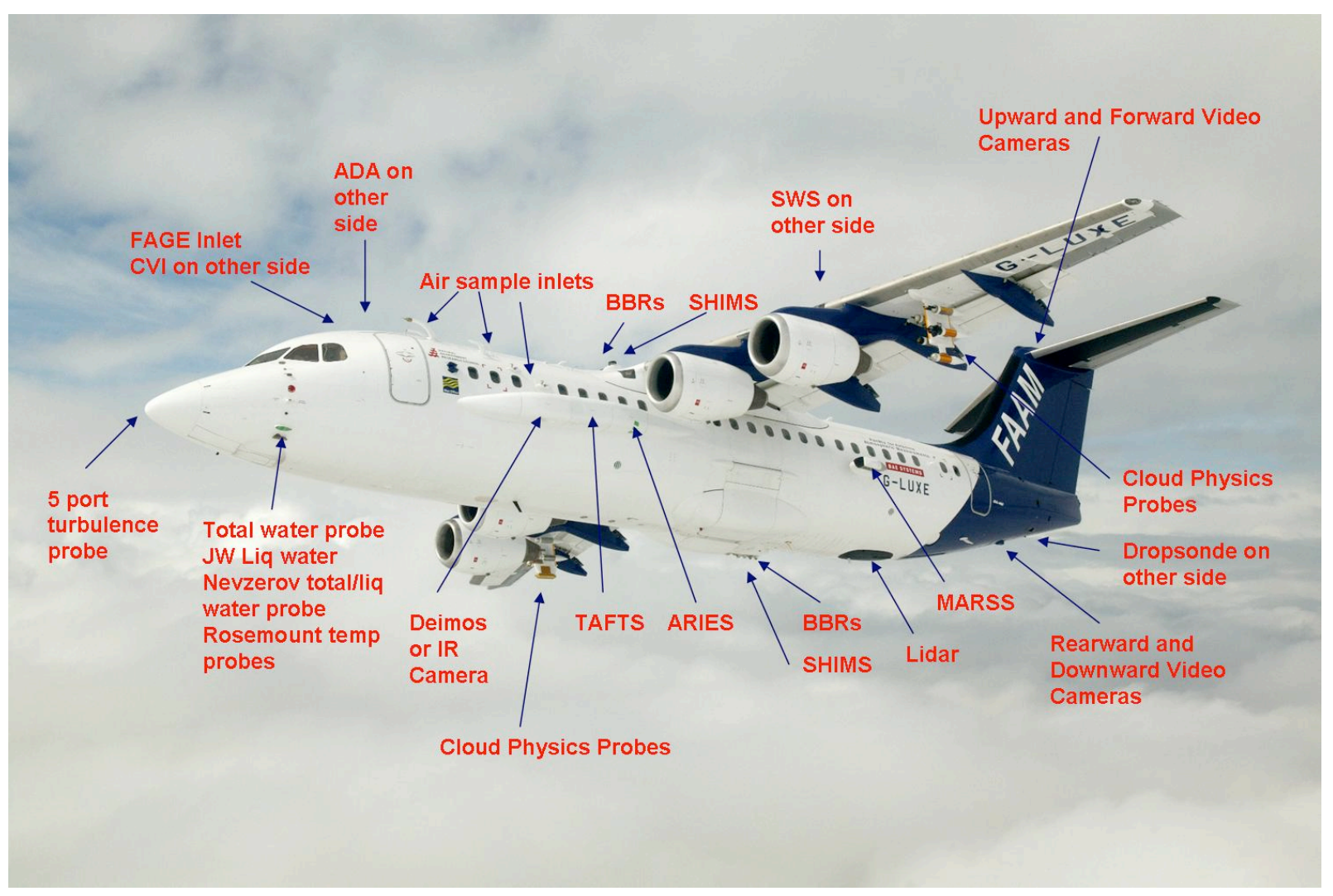

Figure 2 


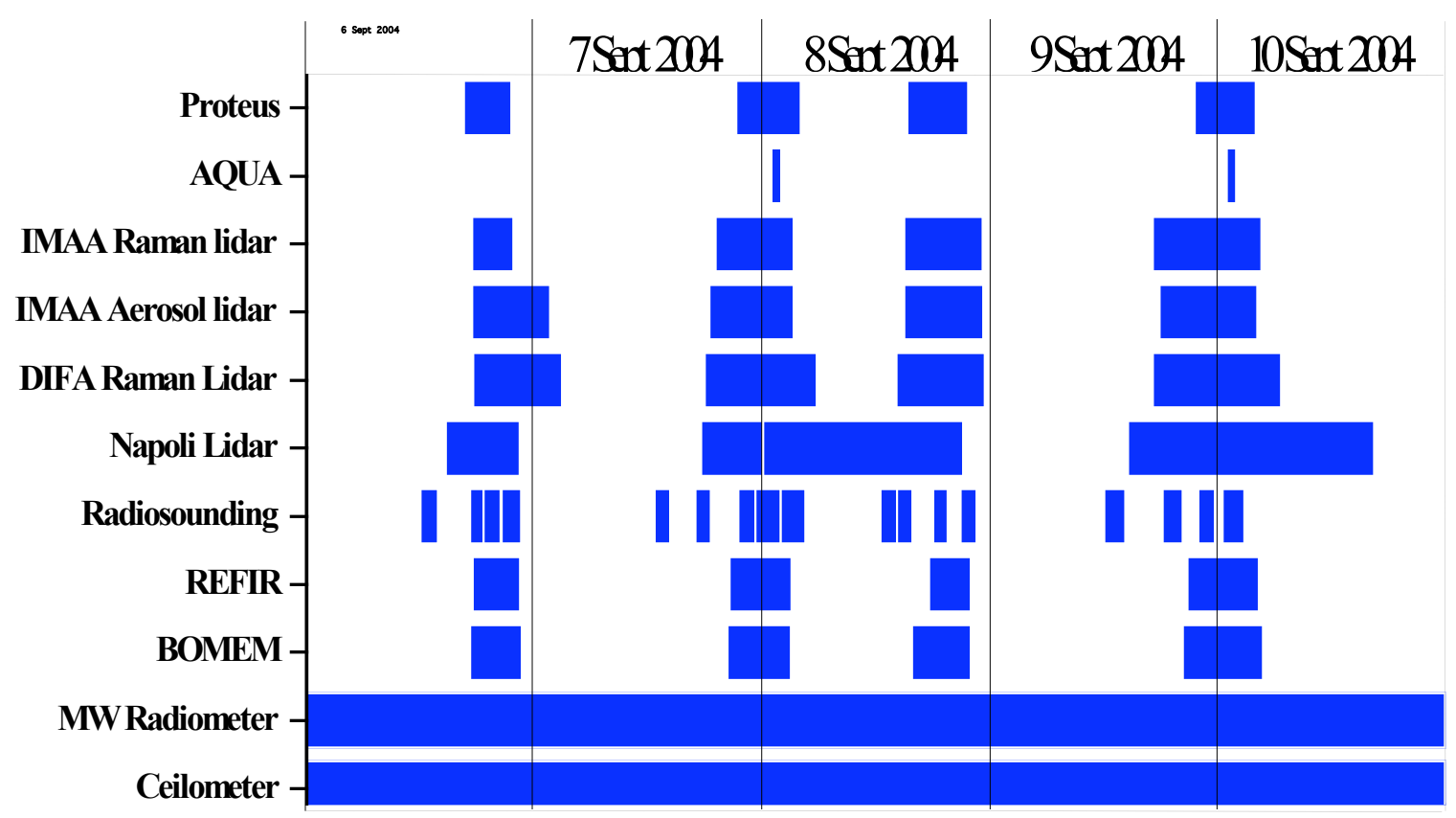

Figure 3 

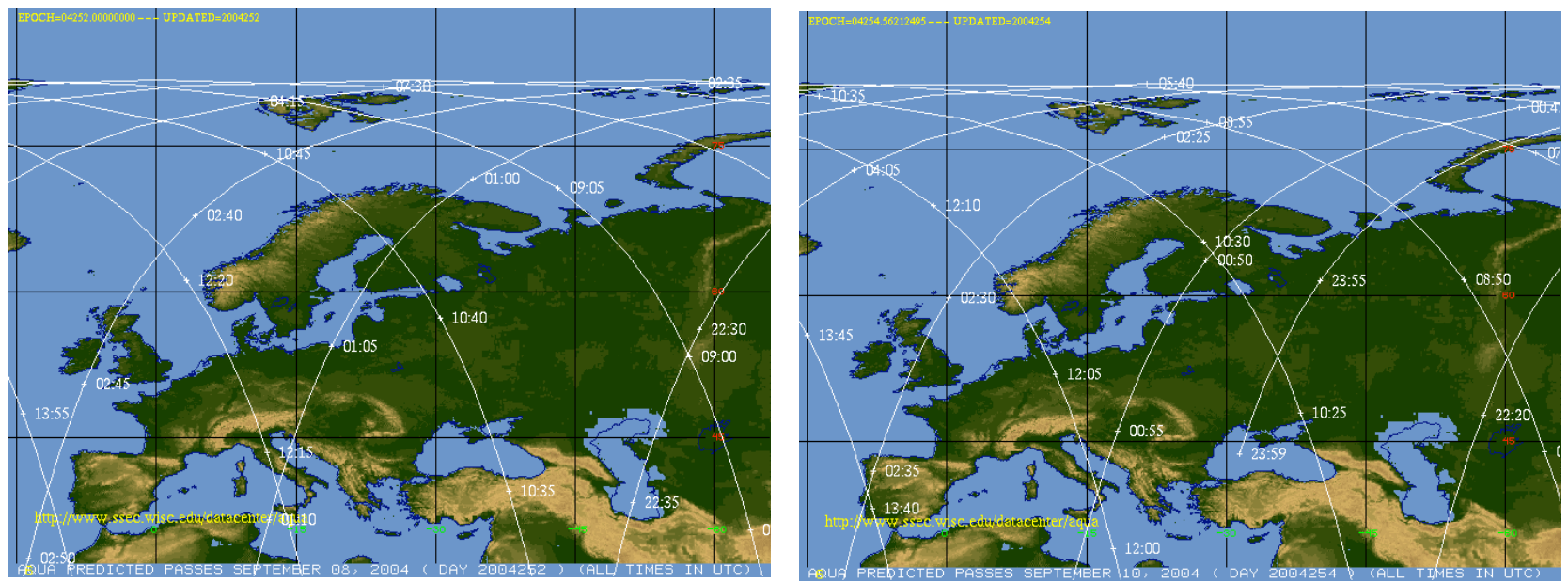

a)

PROTEUS FLIGHT TRACK (Sep. 06, 2004)

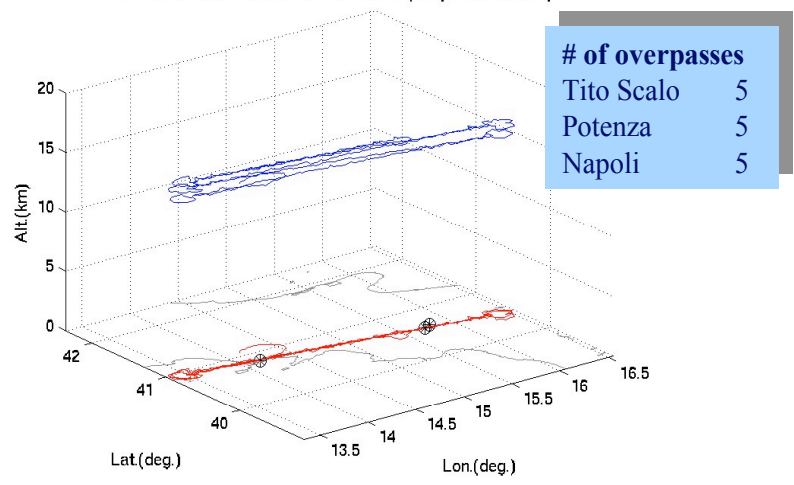

c)

PROTEUS FLIGHT TRACK (Sep. 08, 2004)

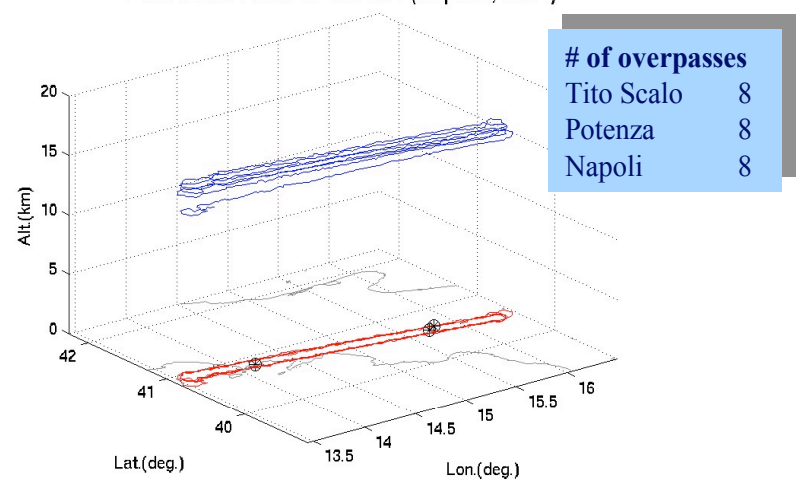

PROTEUS FLIGHT TRACK (Sep. 07, 2004)

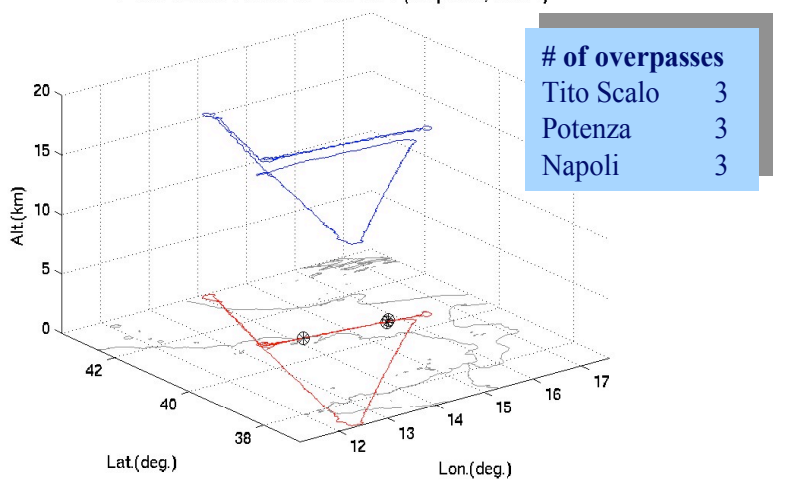

d)

PROTEUS FLIGHT TRACK (Sep. 09, 2004)

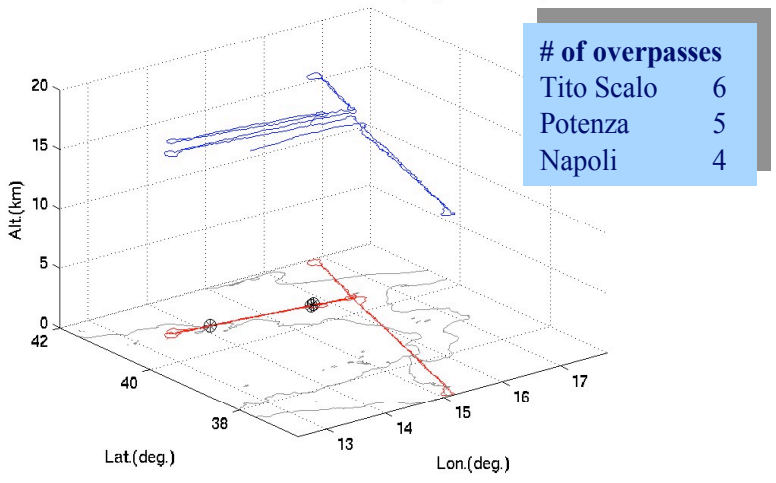

e)

Figure 4 


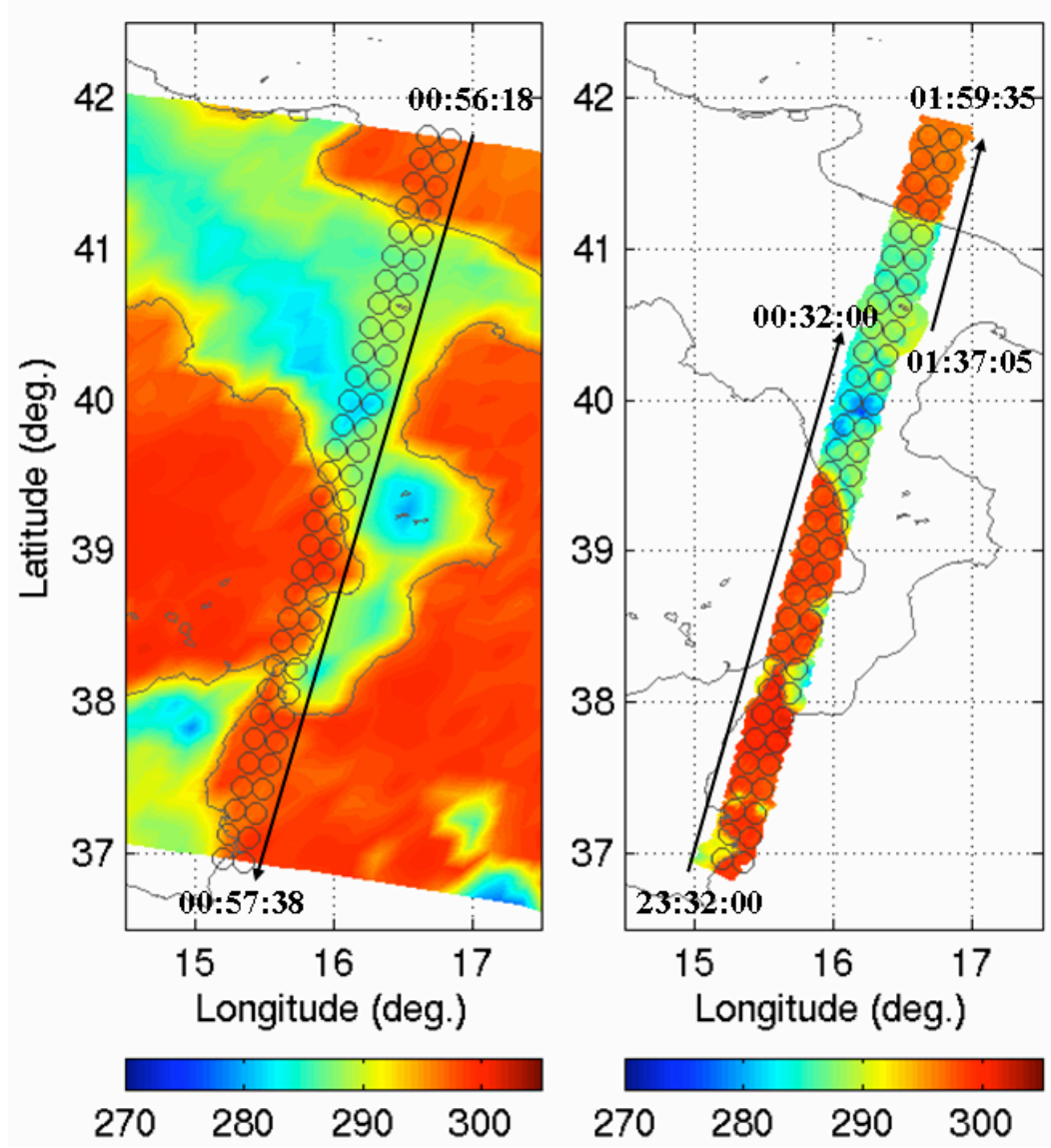

Figure 5 

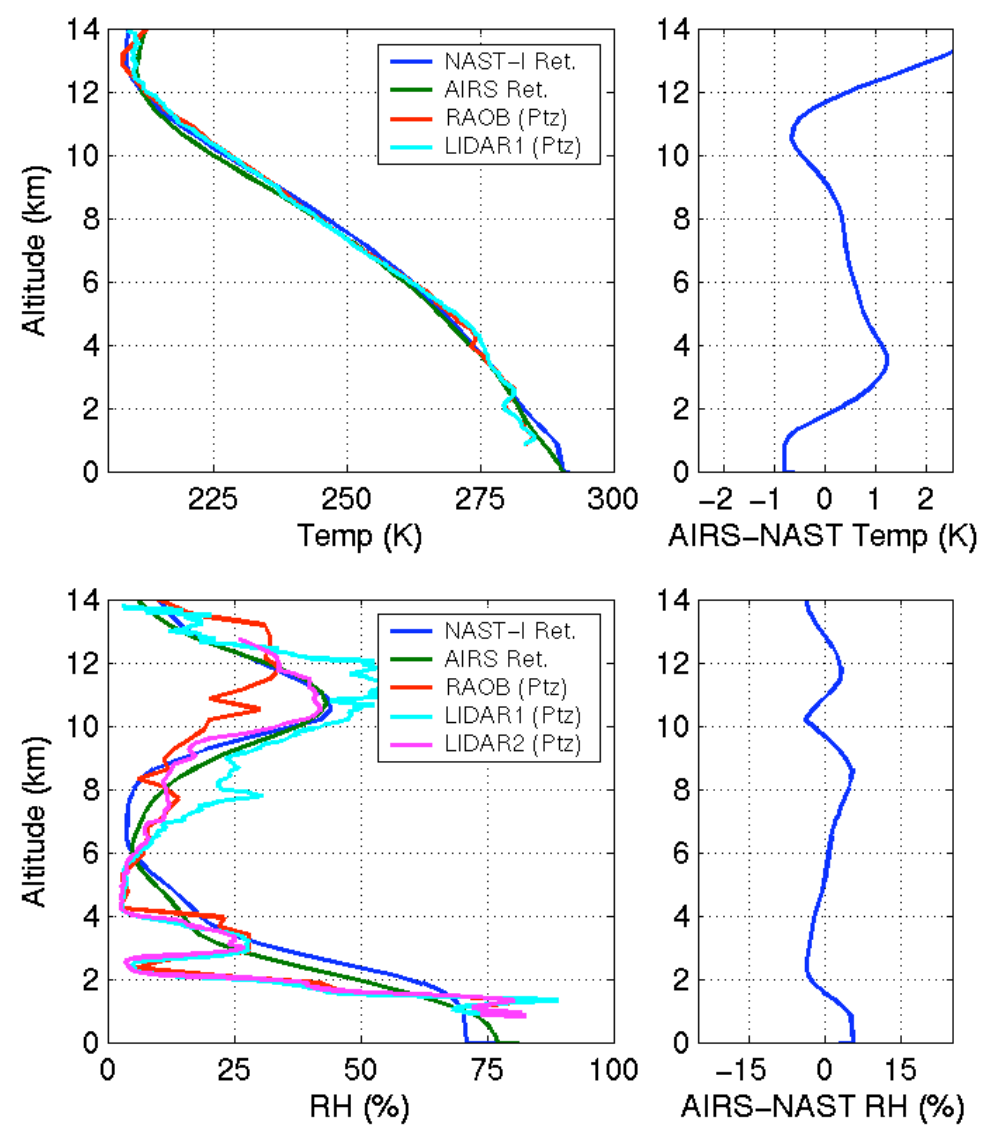

Figure 6 


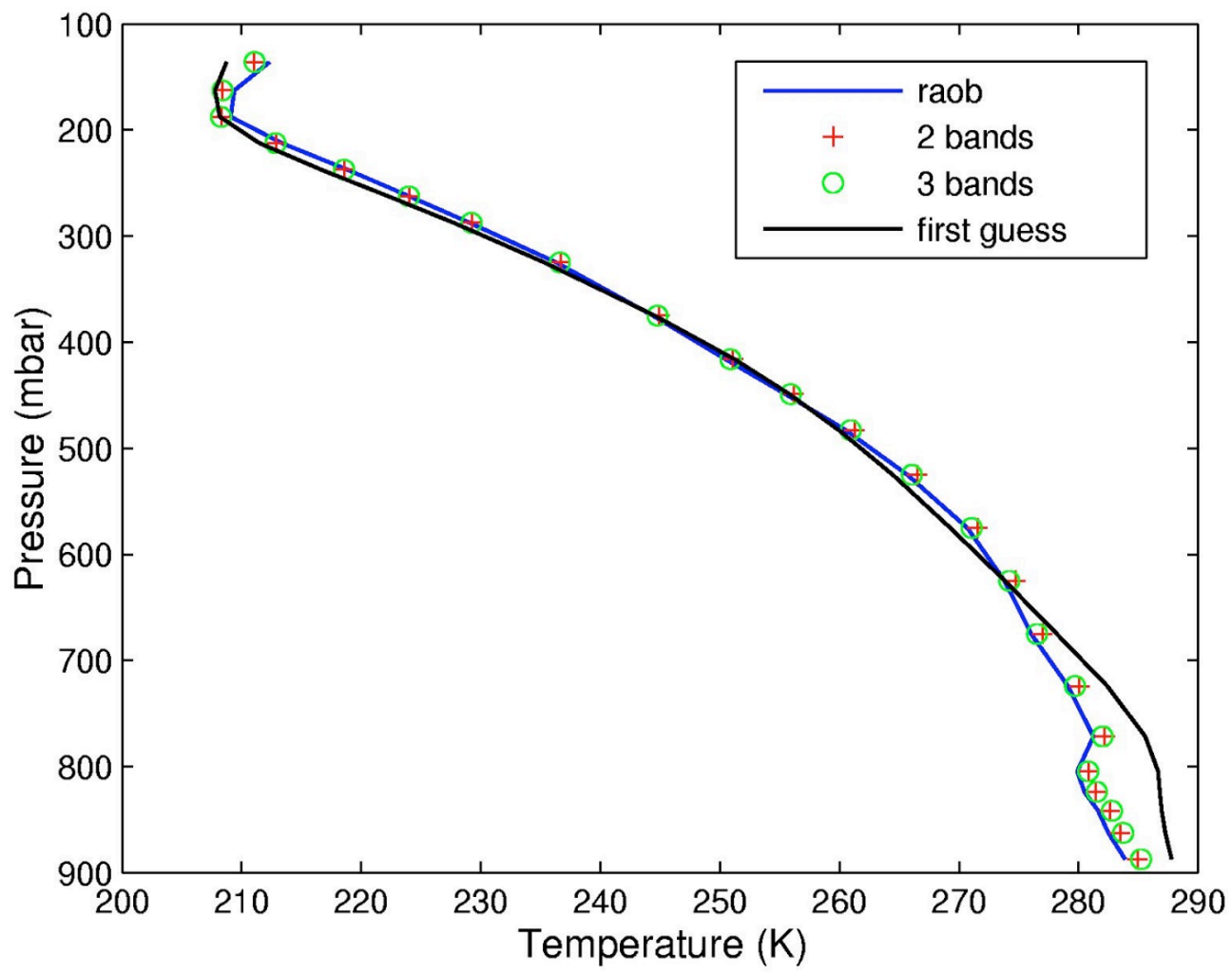

Figure 7 


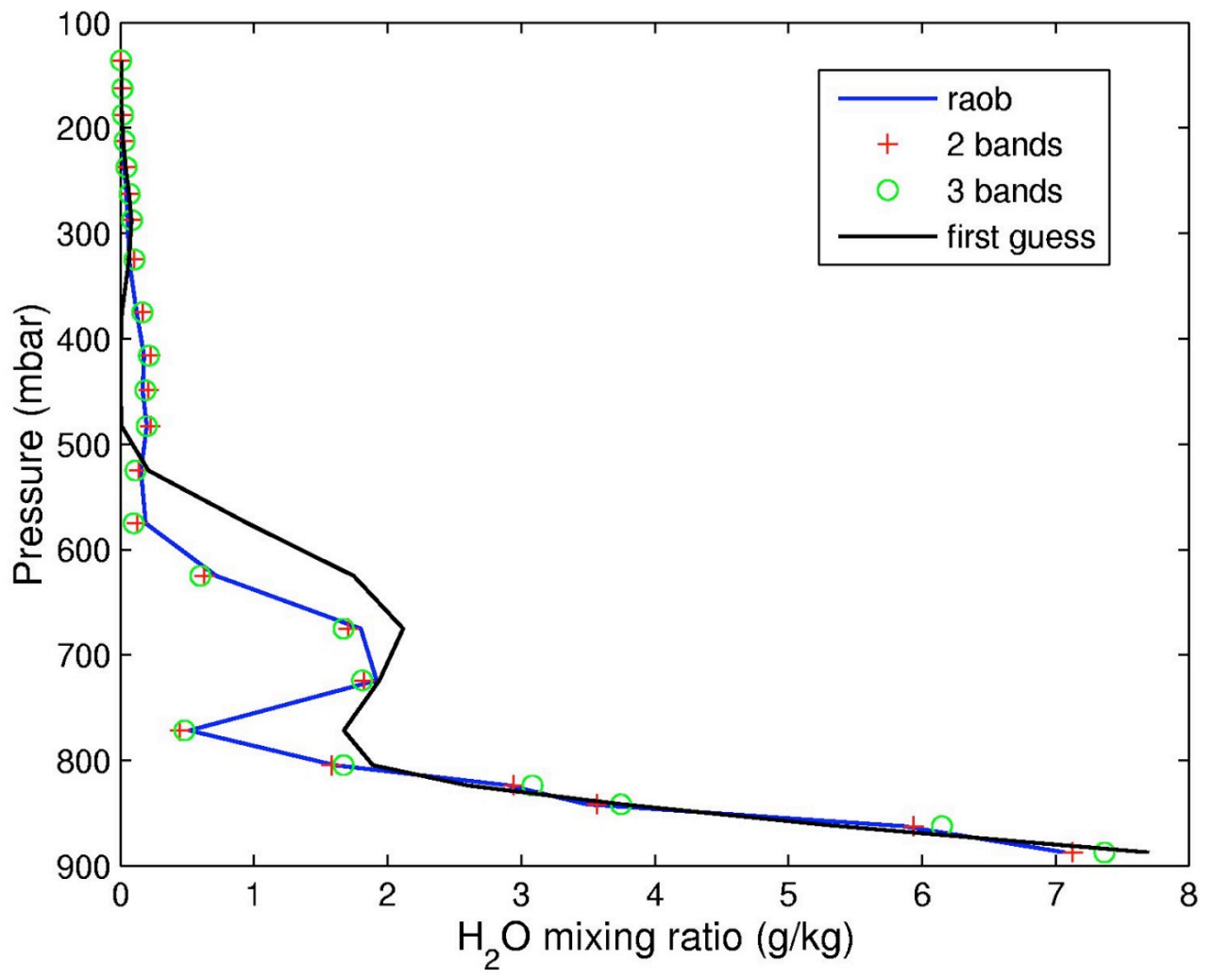

Figure 8 


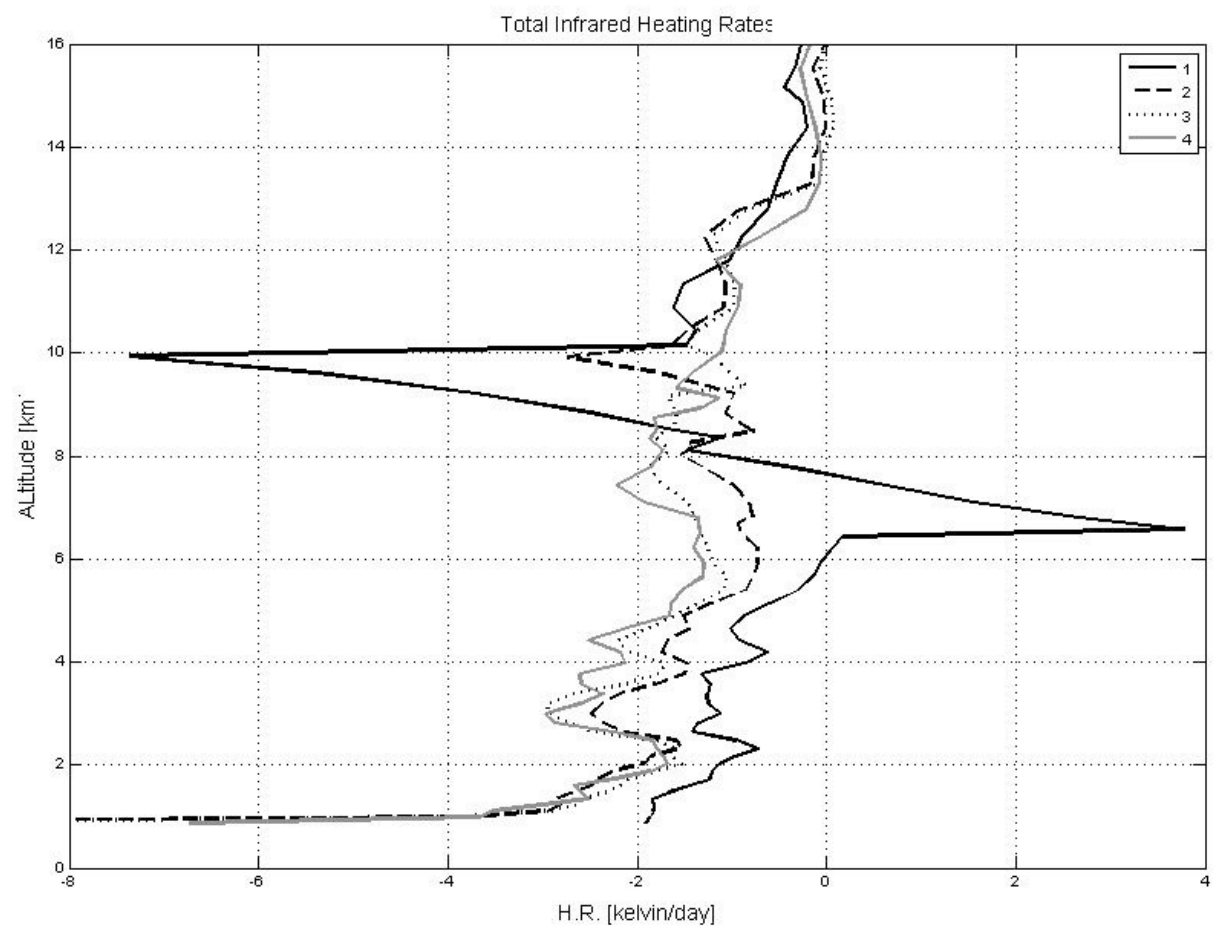

Figure 9 

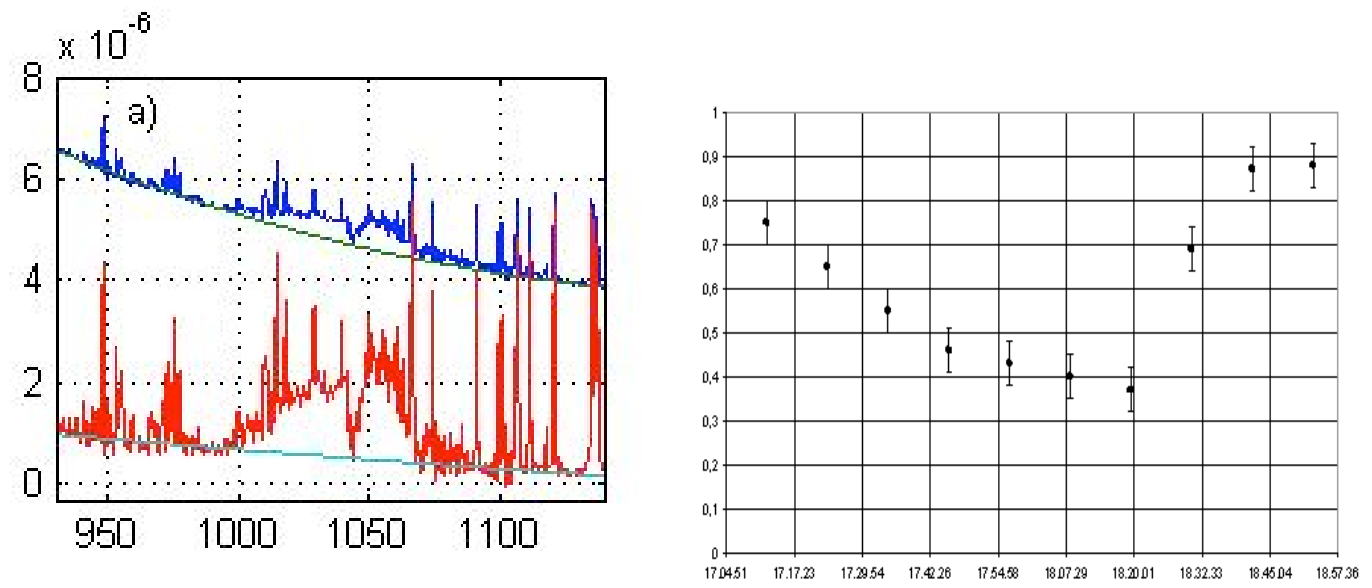

Figure 10 


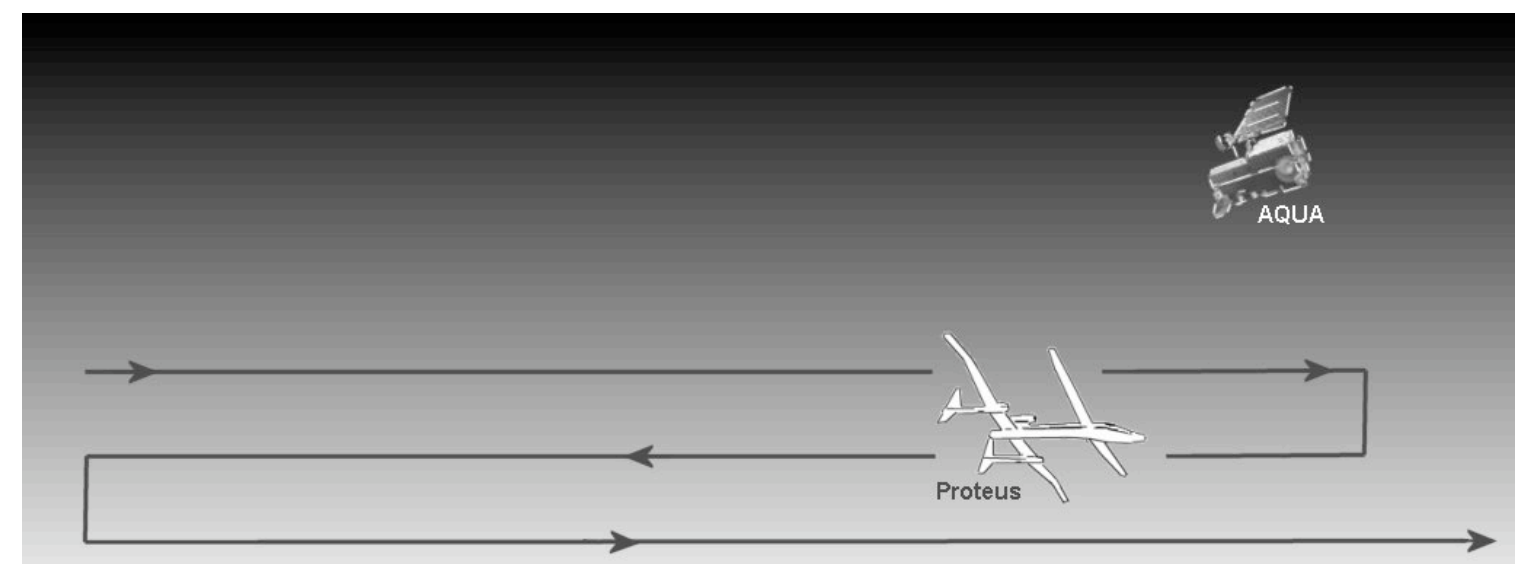

Tropopause

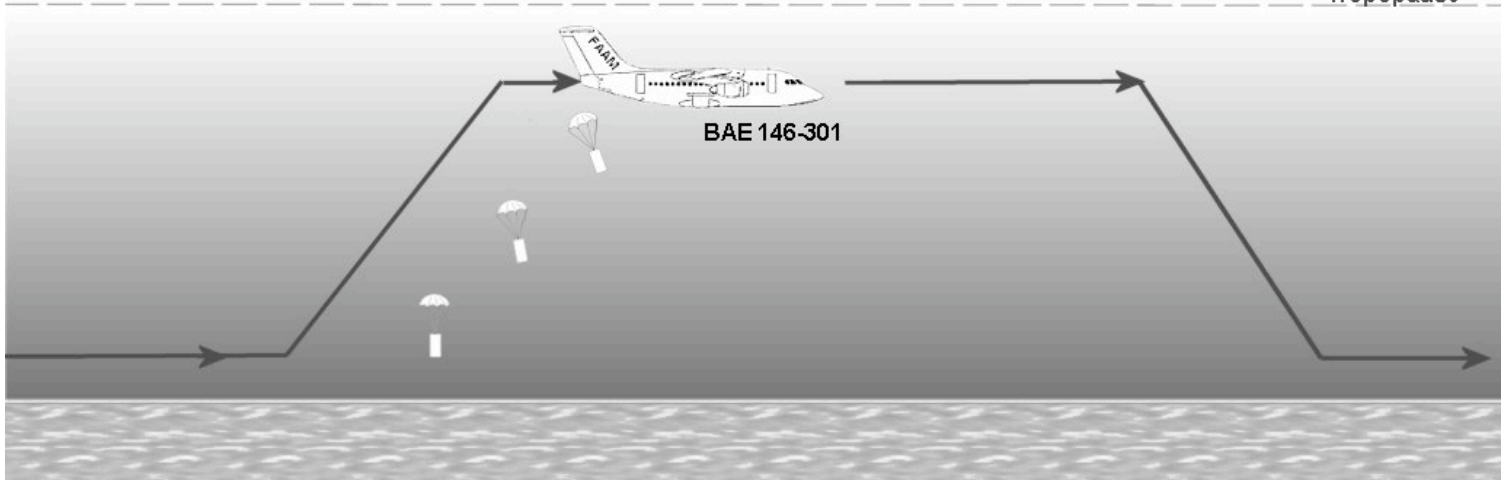

Figure 11

Page 31 of 41 

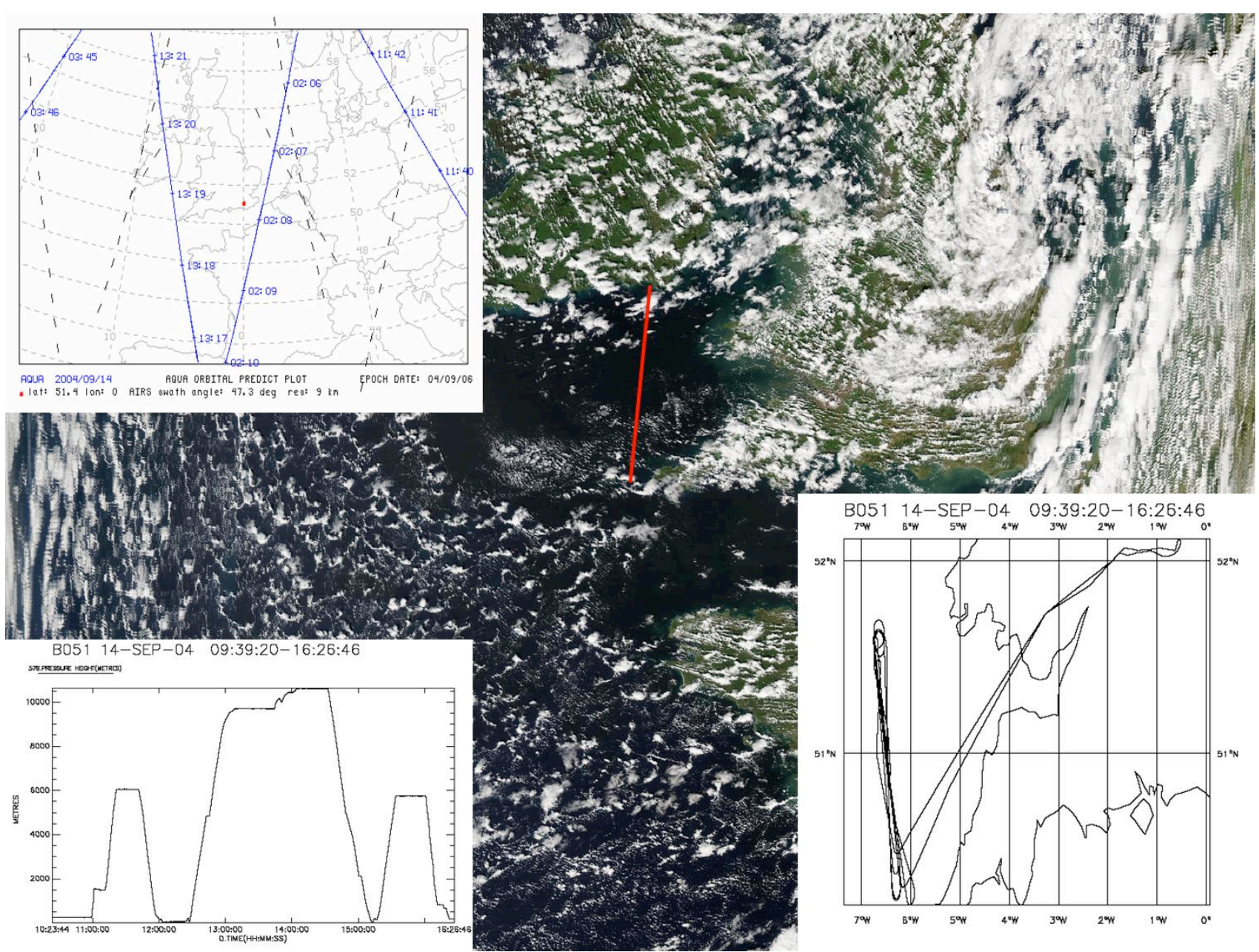

Figure 12 

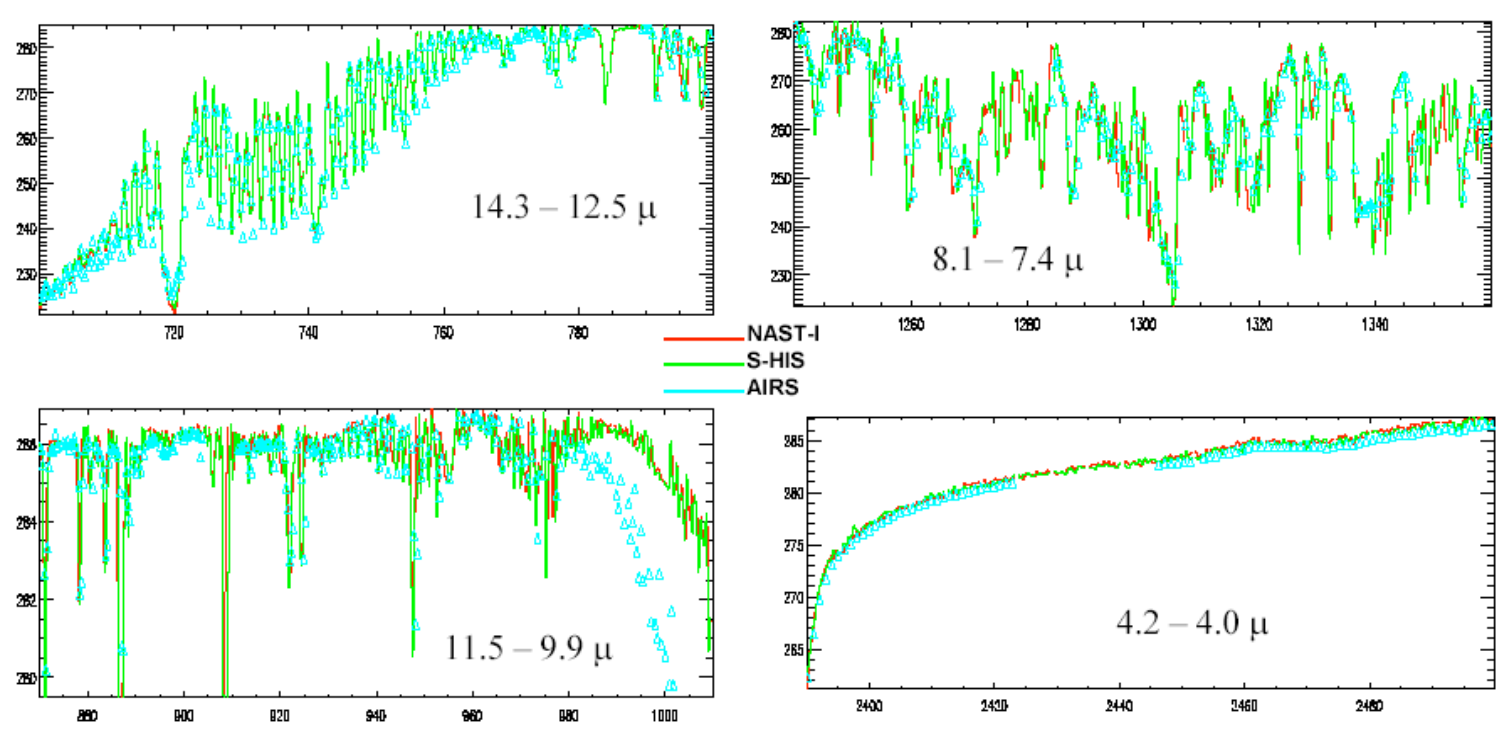

Figure 13 


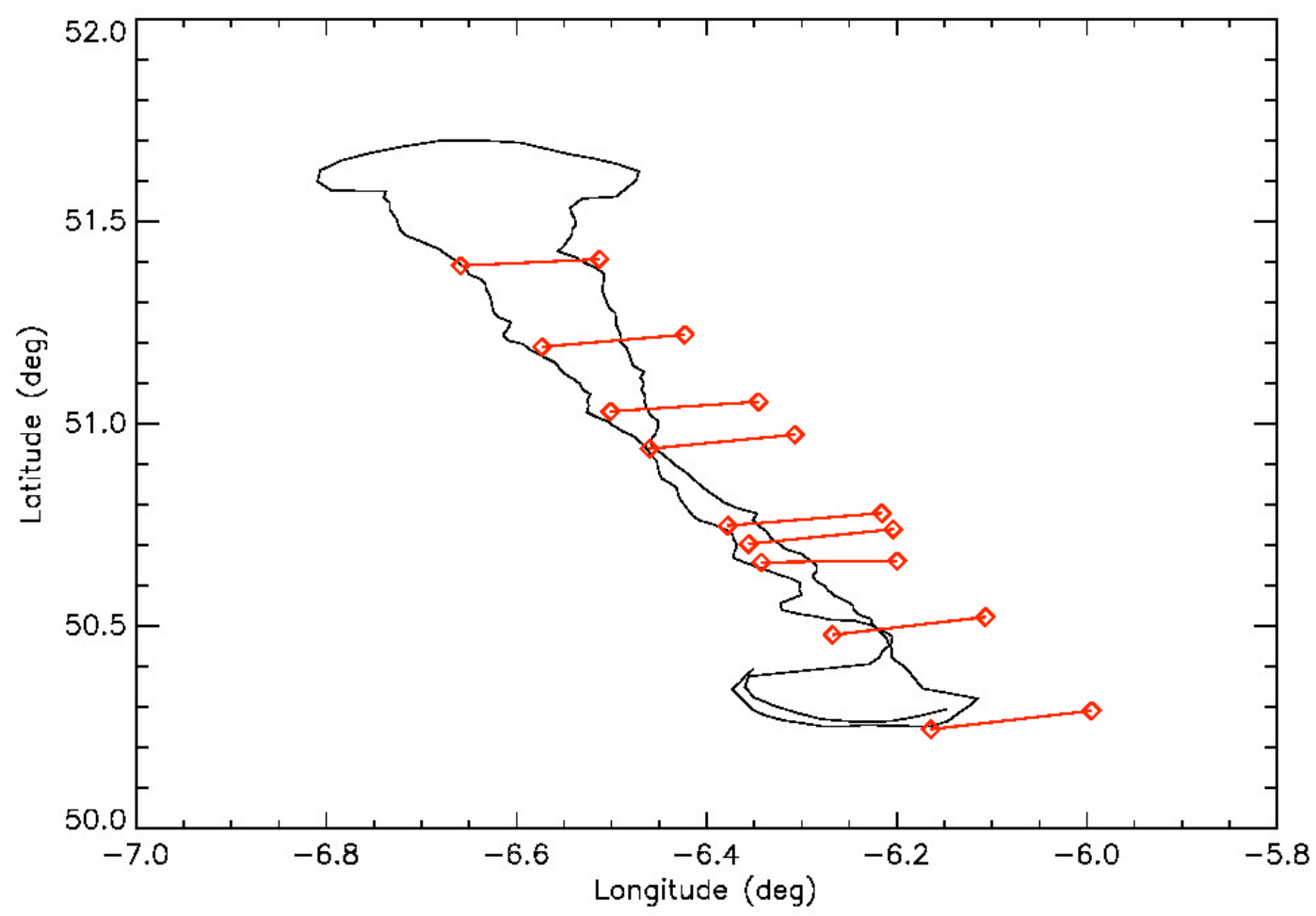

Figure 14 


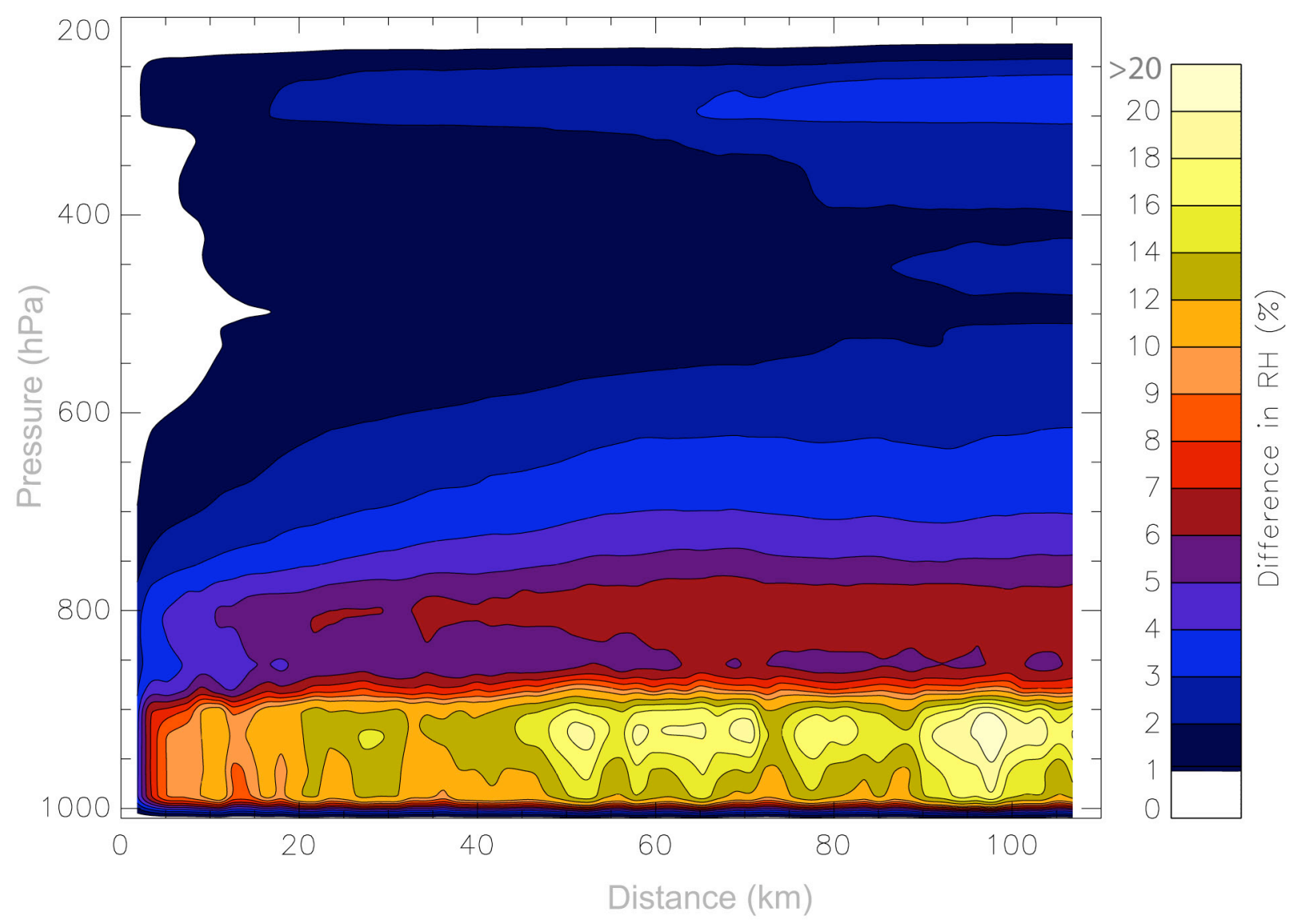

Figure 15

Page 35 of 41 


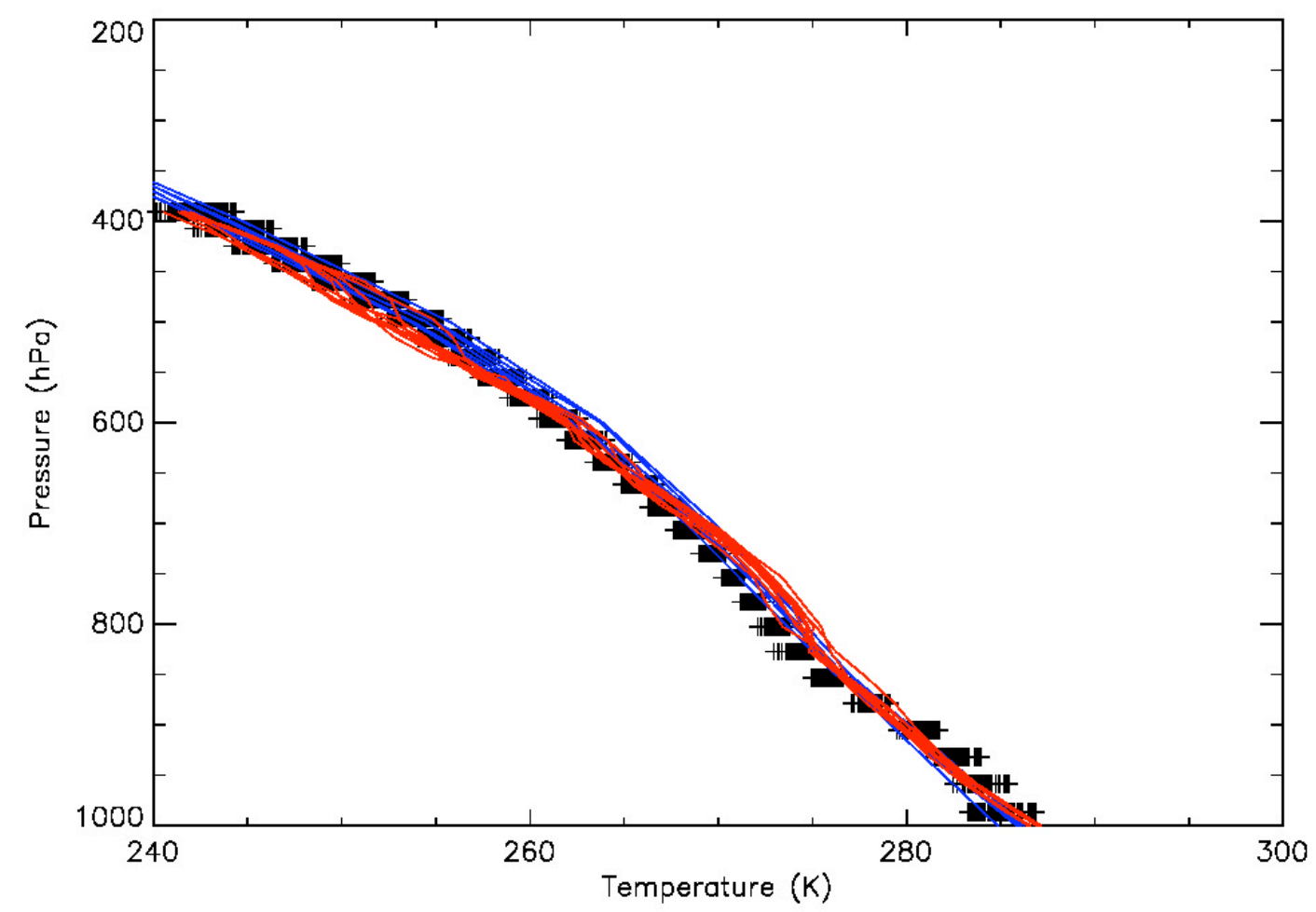

Figure 16 


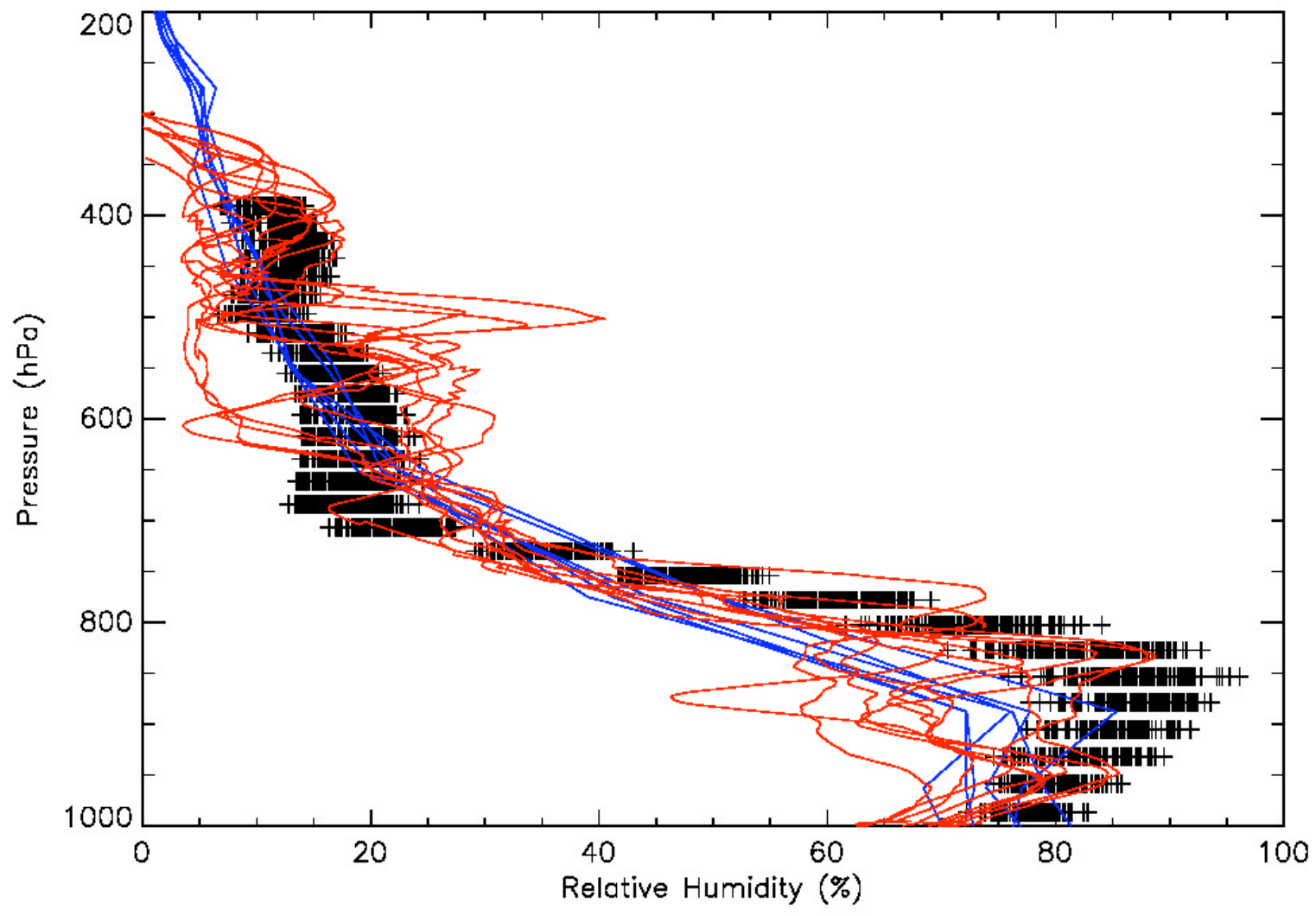

Figure 17 


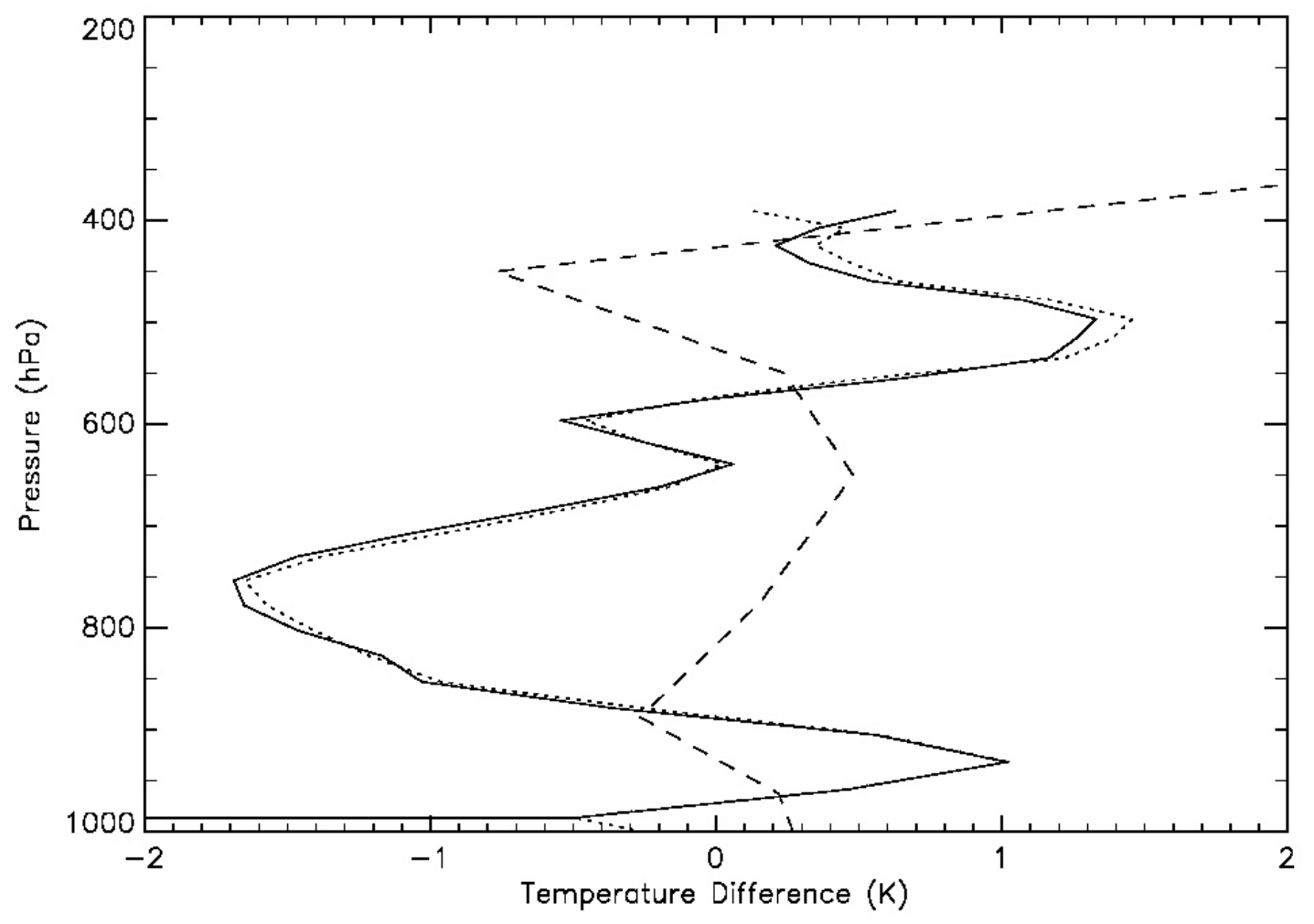

Figure 18 


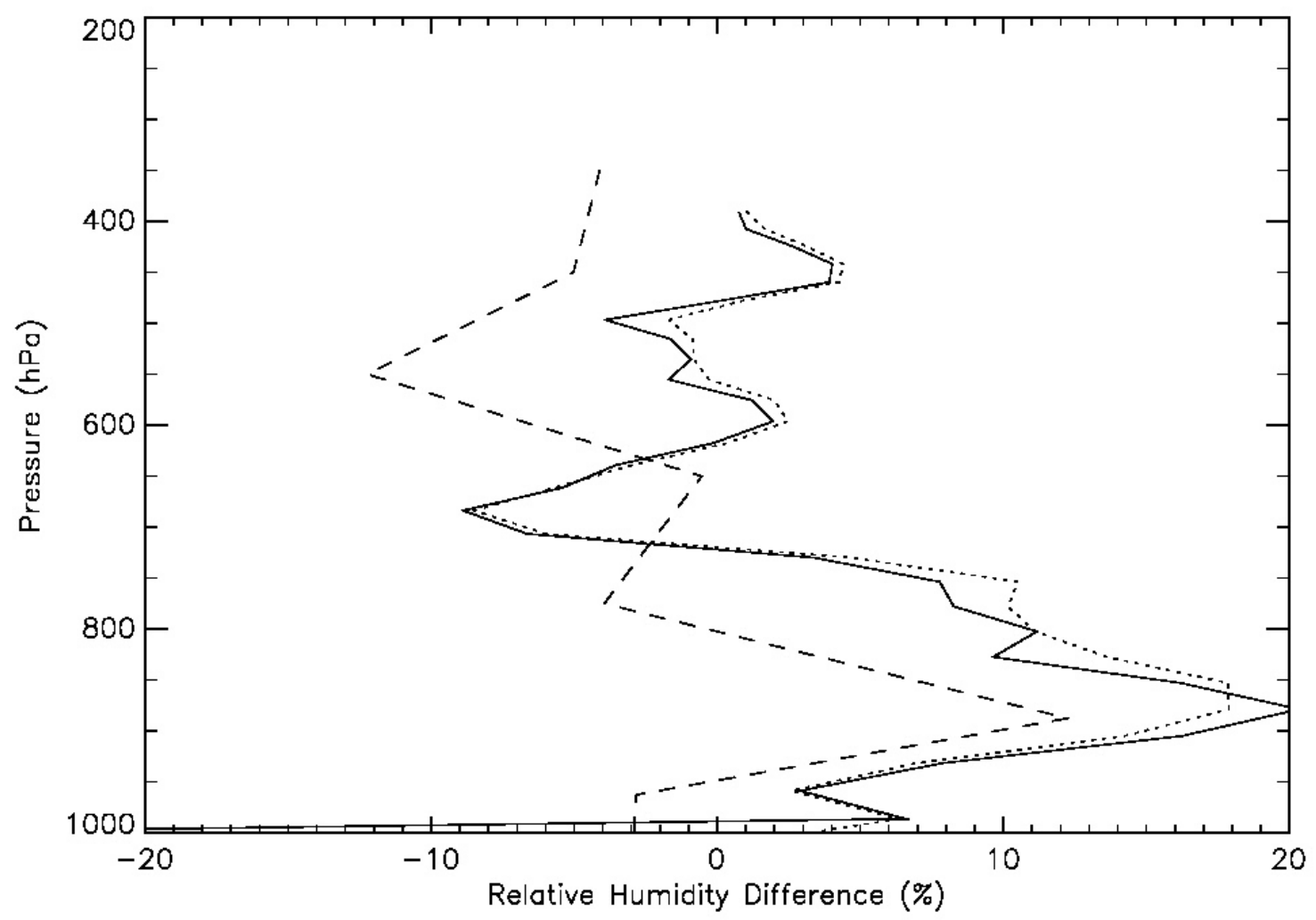

Figure 19 


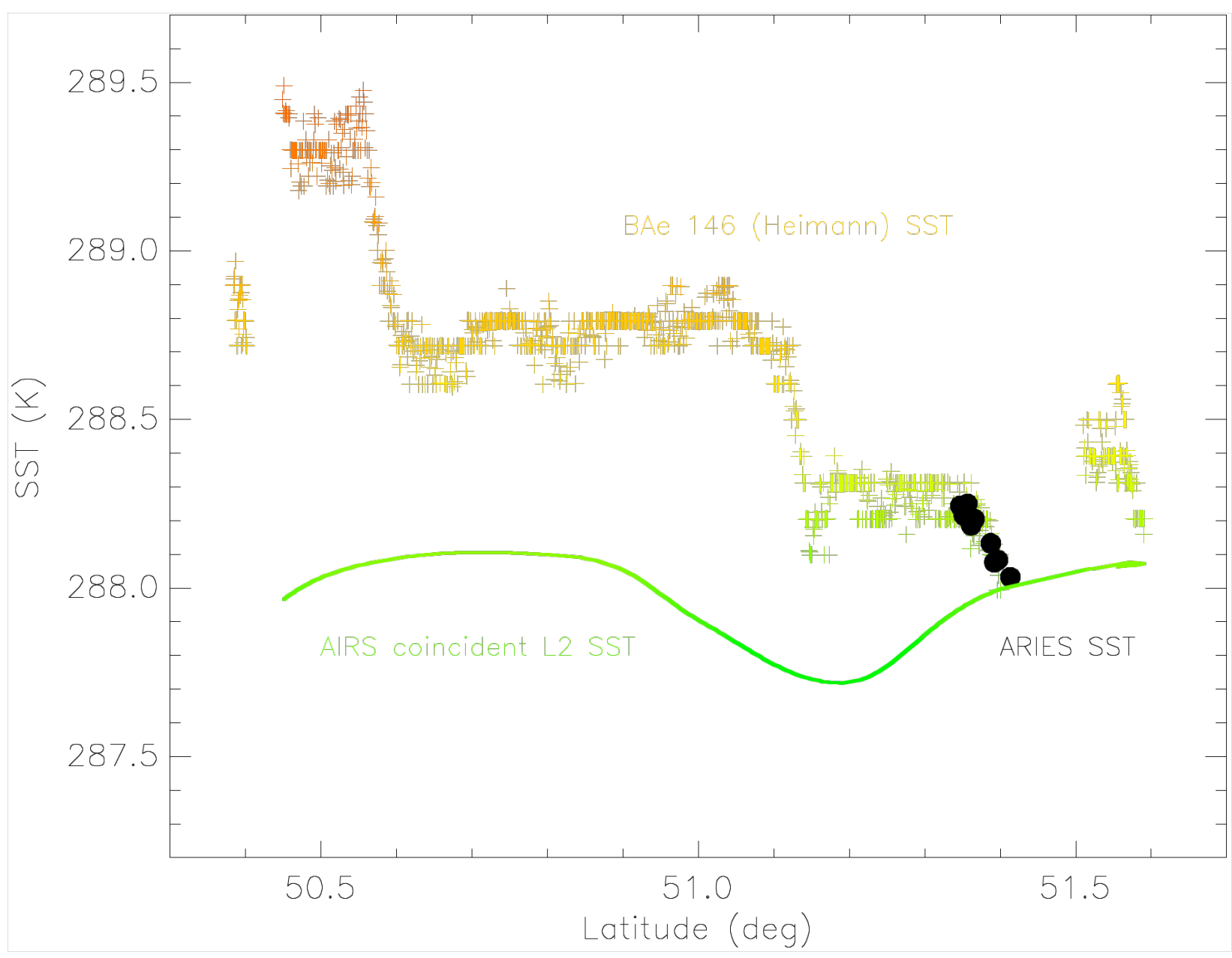

Figure 20

Page 40 of 41 


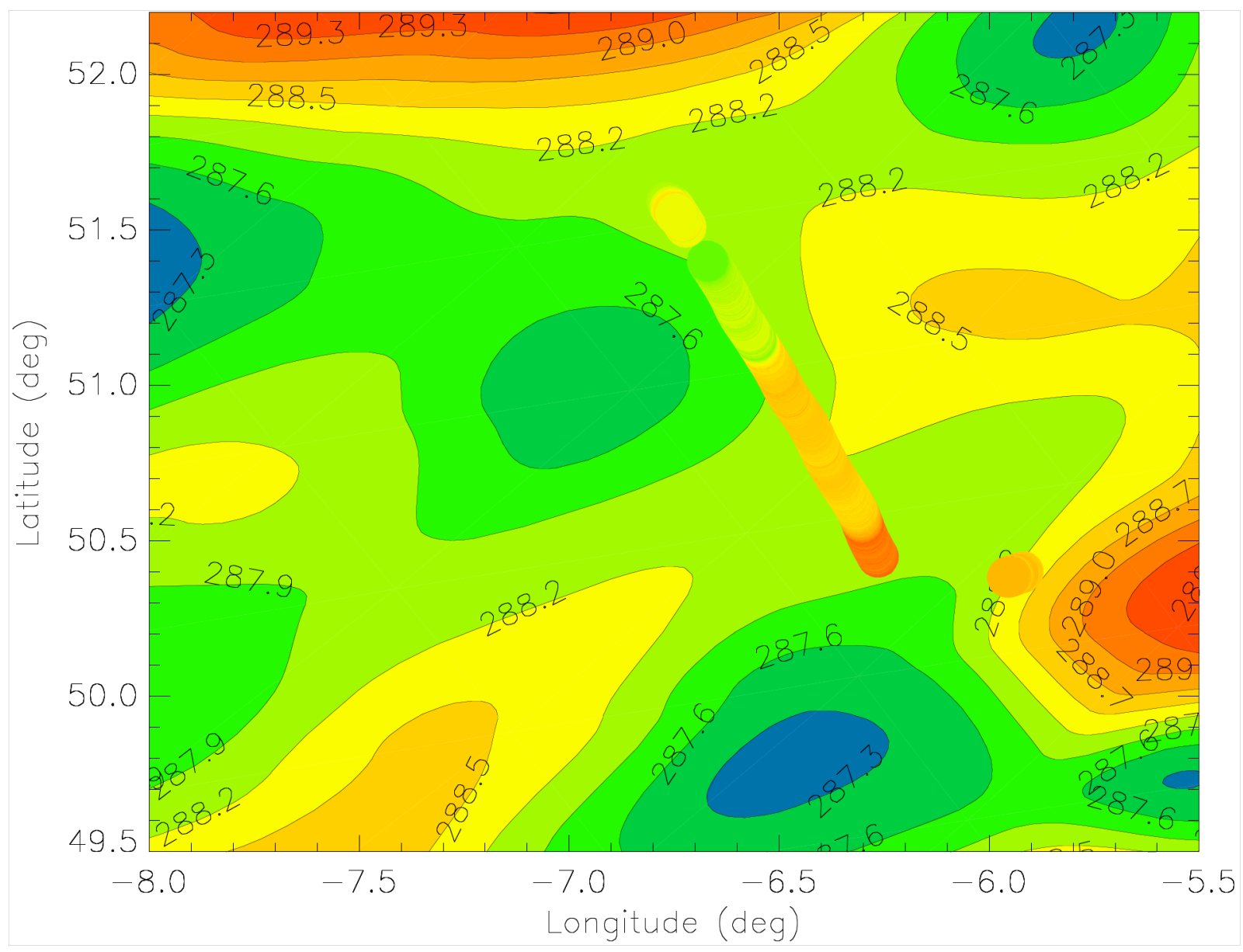

Figure 21 